

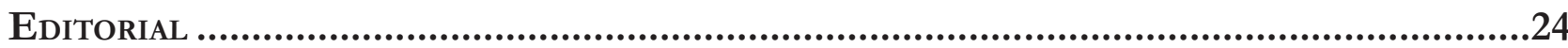

O Direito na fronteira da razão: Psicologia, neurociência e economia comportamental................... 24 Patrícia Perrone Campos Mello e Sergio Nojiri

I. NeURodireito: COGNIÇão, EMOÇÃo, JUÍZOS MORAIS E CIÊNCIA ..........................................26

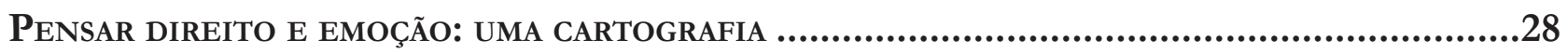

Nevita Maria Pessoa de Aquino Franca Luna

Neurodireito: o início, o fim E O MEIO

Carlos Marden e Leonardo Martins Wykrota

ENSAIO JURÍDICO SOBRE A RACIONALIDADE HUMANA: MAIORES, CAPAZES E IRRACIONAIS

André Perin Schmidt Neto e Eugênio Facchini Neto

DIVERGÊNCIAS DE PRINCÍPIO: ARGUMENTOS JURÍDICOS E MORAIS EM UM CENÁRIO DE DESACORDOS SOCIAIS

André Matos de Almeida Oliveira, Pâmela de Rezende Côrtes e Leonardo Martins Wykrota

CONSILIÊNCIA E A POSSIBILIDADE DO NEURODIREITO: DA DESCONFIANÇA À RECONCILIAÇÃO DISCIPLINAR.....

Thaís de Bessa Gontijo de Oliveira e Renato César Cardoso

MODELOS DE MORALIDADE

Molly J. Crockett

A INFELIZ BUSCA POR FELICIDADE No DiREITo

Úrsula Simões da Costa Cunha Vasconcellost, Noel Struchiner e Ivar Hannikainen

Além da liberdade: PersPeCtivas Em Nietzsche.

Lucas Costa de Oliveira

A mediaÇão de CONFlitos SOb a PERSPECTIVA do DESENVOLVIMENTO HUMANO: AS CONTRIBUIÇÕES DA PSICOLOGIA POSITIVA

Simone de Biazzi Ávila Batista da Silveira e Deise Brião Ferraz

Neuroimagiologia e aValiação de ResPonsabilidade

Nicole A. Vincent 
ANÁLISE CRÍTICA DA ORIENTAÇÃO DE CIDADÃOS COMO MÉTODO PARA OTIMIZAR DECISÕES PÚBLICAS POR MEIO DA TÉCNICA NUDGE.

Luciana Cristina Souza, Karen Tobias França Ramos e Sônia Carolina Romão Viana Perdigão

Políticas públicas e o deVer de monitoramento: “LEVANdo os Direitos A SÉrio". .252 Ana Paula de Barcellos

Nudges E POLÍticas PÚblicas: uM MECANISMO DE COMBATE AO TRABALHO EM CONDIÇÃo ANÁLOGA À DE ESCRAVO .267

Amanda Carolina Souza Silva, Débhora Renata Nunes Rodrigues e Saul Duarte Tibaldi

REDUZINDO A TRIBUTAÇÃO COGNITIVA: LIÇÕES COMPORTAMENTAIS PARA A DIMINUIÇÃO DOS EFEITOS PSICOLÓGICOS ADVERSOS DA POBREZA.............................................................288 Leandro Novais e Silva, Luiz Felipe Drummond Teixeira, Gabriel Salgueiro Soares e Otávio Augusto Andrade Santos

Políticas PÚBLICAS EM SUICÍDIO: DO PATERNALISMO CLÁSSICO AO PATERNALISMO LIBERTÁRIO E NUDGING

Davi de Paiva Costa Tangerino, Gabriel Cabral e Henrique Olive

Nudges COMO POLÍticA PÚbliCA PARA AUMENTAR O ESCASSO NÚMERO DE DOADORES DE ÓRGÃos PARA TRANSPLANTE

Roberta Marina Cioatto e Adriana de Alencar Gomes Pinheiro

Os PROGRAMAS DE INTEGRIDADE PARA CONTRATAÇÃO COM A ADMINISTRAÇÃO PÚBLICA ESTADUAL: NUDGE OU OBRIGAÇÃo LEGAL? UM OLHAR SOBRE AS DUAS PERSPECTIVAS .386

Cíntia Muniz Rebouças de Alencar Araripe e Raquel Cavalcanti Ramos Machado

Paternalismo libertário e Proteção JURídica do AMbiente: POR QUe PROTEger o AMBIENTE TAMBÉM DEVE SER PROTEGER AS LIBERDADES?

Mariana Carvalho Victor Coelho e Patryck de Araujo Ayala

Políticas PÚblicas baseadas EM EVIdÊNCIAS COMPORTAMENTAIS: REFLEXões A PARTIR do Projeto de Lei 488/2017 do Senado

Pâmela de Rezende Côrtes, André Matos de Almeida Oliveira e Fabiano Teodoro de Rezende Lara

III. ECONOMIA COMPORTAMENTAL: VIESES COGNITIVOS E POLÍTICAS PÚBLICAS .455

ECONOMIA COMPORTAMENTAL E DIREITO: A RACIONALIDADE EM MUDANÇA Marcia Carla Pereira Ribeiro e Victor Hugo Domingues

VIESES COGNITIVOS E DESENHO DE POLÍTICAS PÚBLICAS 
A neurociênCia da moralidade na tomada de DeCisões Jurídicas Complexas e No DESENHO DE POLÍTICAS PÚBLICAS

Erik Navarro Wolkart

Desvio de CARÁter ou SIMPLESMENTE HUMANO? ECONOMIA COMPORTAMENTAL APLICADA AO COMPORTAMENTO DESONESTO

Diana Orghian, Gabriel Cabral, André Pinto e Alessandra Fontana

Políticas Públicas e a ConcretizaÇão de direitos sociais: TOMAdA DE DECisão, ARQUITETURA DE ESCOLHAS E EFETIVIDADE

Ana Elizabeth Neirão Reymão e Ricardo dos Santos Caçapietra

BEHAVIORAL ECONOMICS E DIREITO DO CONSUMIDOR: NOVAS PERSPECTIVAS PARA O ENFRENTAMENTO DO SUPERENDIVIDAMENTO .568

Samir Alves Daura

A EDUCAÇÃo FORMAL PARA O CONSUMO É GARANTIA PARA UMA PRESENÇA REFLETIDA DO CONSUMIDOR NO MERCADO? UMA ANÁLISE COM BASE NA BEHAVIORAL LAW AND ECONOMICS (ECONOMIA COMPORTAMENTAL) 600

Marcia Carla Pereira Ribeiro e Edson Mitsuo Tiujo

LIBET, DETERMINISMO E CONSUMO: AS INFLUÊNCIAS DO MARKETING E A RELEVÂNCIA DA DELIBERAÇÃo CONSCIENTE NA SUPERAÇÃo CONDICIONAL DE HÁBITOS DE CONSUMO PERIGOSOS616 Émilien Vilas Boas Reis e Leonardo Cordeiro de Gusmão

CiÊNCIA DO DIREITO TRIBUTÁRIO, ECONOMIA COMPORTAMENTAL E EXTRAFISCALIDADE. .640 Hugo de Brito Machado Segundo

IV. CoMportamento JUdiCiAL: INFLUÊNCIA DE FATORES EXTRAJURÍDicos .660

FATORES METAPROCESSUAIS E SUAS INFLUÊNCIAS PARA A FORMAÇÃo DA DECISÃo JUDICIAL .662 Rogério Roberto Gonçalves de Abreu, Lúcio Grassi de Gouveia e Virgínia Colares

“A VIDA COMO ELA É": COMPORTAMENTO ESTRATÉGICO NAS CORTES Patrícia Perrone Campos Mello

A COMPOSIÇÃo do ÓRGão COLEGIAdo E SEUS EFEITOS NA TOMADA DE DECISÃo .720 André Garcia Leão Reis Valadares

Das 11 ilhas ao centro do arquipélago: os superpoderes do Presidente do STF DURANTE O RECESSO JUDICIAL E FÉRIAS .741 José Mário Wanderley Gomes Neto e Flávia Danielle Santiago Lima 
RAZÃo, EMOÇÃo E DELIBERAÇÃO: AS ADEQUAÇÕES REgIMENTAIS do SUPERIOR TribUNAL DE JUSTIÇA PARA A FORMAÇÃo DE PRECEDENTES EFICAZES

Peter Panutto e Lana Olivi Chaim

Heurística de ancoragem e fiXaÇÃo de danos morais em JUizados especiais Cíveis no Rio DE JANEIRO: UMA NOVA ANÁLISE 778

Fernando Leal e Leandro Molhano Ribeiro

LA PROTECCIÓN DE LOS DERECHOS POLÍTICOS FRENTE A LAS FUNCIONES DISCIPLINARIAS DE LAS AUTORIDADES ADMINISTRATIVAS: SUBSIDIARIEDAD Y DEFERENCIA EN EL SISTEMA INTERAMERICANO DE DERECHOS HUMANOS Jorge Ernesto Roa Roa

V. A influênCia do gÊNERo no PROCESSO DECisório JUdiCial

Como os Juízes decidem os Casos de estupro? ANALISANDo SENTENÇAS SOb A PERSPECTIVA DE VIESES E ESTEREÓTIPOS DE GÊNERO 826 Gabriela Perissinotto de Almeida e Sérgio Nojiri

GÊNERO E COMPORTAMENTO JUDICIAL NO SUPREMO TRIBUNAL FEDERAL: OS MINISTROS CONFIAM MENOS EM RELATORAS MULHERES?

Juliana Cesario Alvim Gomes, Rafaela Nogueira e Diego Werneck Arguelhes

Hércules, Hermes e a Pequena Sereia: uma reflexão sobre estereótipos de gênero, SUBPRESENTAÇÃo DAS MULHERES NOS TRIBUNAIS E (I)LEGITIMIDADE DEMOCRÁTICA DO PODER JUDICIÁRIO. .878 Jane Reis Gonçalves Pereira e Renan Medeiros de Oliveira

Prisão Cautelar de gestantes: análise do Fundamento filosófico da decisão do Habeas CoRpus N. 143.641 912

Artur César Souza e Giovania Tatibana de Souza

VI. Neurodireito APlicado ao direito E Ao Processo PENAL....................................926

CÉREbros QUe PUNEM: UMA REVISÃo CRÍTICA DA NEURoCIÊNCIA DA PUNIÇÃo .....................928 Ricardo de Lins e Horta

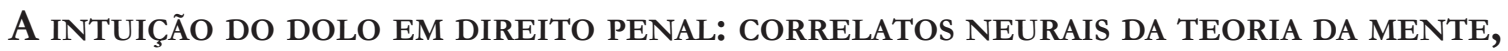
RACIOCÍNIO INDUTIVO E A GARANTIA DA CONVICÇÃO JUSTIFICADA. .946 Thiago Dias de Matos Diniz e Renato César Cardoso

As COMUNIDADES EPISTÊMICAS PENAIS E A PRODUÇÃo LEGISLATIVA EM MATÉRIA CRIMINAL..... 961 Stéphane Enguéléguélé 
DELINQUÊNCIA JUVENIL: RELAÇÕES ENTRE DESENVOLVIMENTO, FUNÇÕES EXECUTIVAS E COMPORTAMENTO SOCIAL NA ADOLESCÊNCIA .

André Vilela Komatsu, Rafaelle CS Costa e Marina Rezende Bazon

Límites TEMPORALES A LAS PENAS PRIVATIVAS DE LIBERTAD ATENDIENDO AL DESARROLLO PSICOSOCIAL.

Silvio Cuneo Nash

NEURolaw E AS PERSPECTIVAS PARA UMA ANÁLISE OBJETIVA DO COMPORTAMENTO SUGESTIONADO: REPERCUSSÃO DAS FALSAS MEMÓRIAS NA ESFERA PENAL

Mariana Dionísio de Andrade, Marina Andrade Cartaxo e Rafael Gonçalves Mota

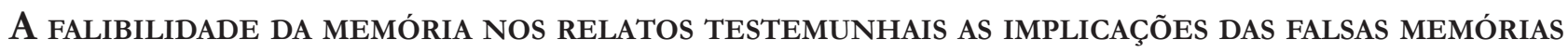
NO CONTEXTO DOS CRIMES CONTRA A DIGNIDADE SEXUAL

Caroline Navas Viana

A (IR)REPETIBILIDADE dA PROVA PENAL DEPENDENTE DA MEMÓRIA: UMA DisCUSSÃo COM BASE NA PSICOLOGIA DO TESTEMUNHO. 1058

William Weber Cecconello, Gustavo Noronha de Avila e Lilian Milnitsky Stein 


\section{Gênero e comportamento judicial no supremo tribunal federal: os ministros confiam menos em relatoras mulheres?*}

\author{
Gender relations and judicial behavior in the \\ brazilian supreme court: do justices distrust \\ female rapporteurs?
}

\author{
Juliana Cesario Alvim Gomes** \\ Rafaela Nogueira*** \\ Diego Werneck Arguelhes****
}

* Recebido em 31/05/2018

Aprovado em 13/07/2018

** Doutoranda e Mestre em Direito pela Universidade do Estado do Rio de Janeiro (UERJ). Master of Laws (LL.M.) pela Universidade Yale (EUA). Email: julianacesarioalvim@gmail.com

*** Professora da FGV Direito Rio. Doutora em Economia pela EPGE/FGV. Email: rafaela. nogueira@fgv.br

**** Professor da FGV Direito Rio. Doutor em Direito pela Universidade Yale (EUA). Email: dwarguelhes@gmail.com

Uma versão preliminar desses dados foi apresentada na conferência "Beyond buman rights? rethinking gender equality in law and politics", realizada em Outubro de 2017, em Bogotá. Gostaríamos de agradecer aos participantes do evento pelas úteis críticas e debates. Gostaríamos também de agradecer a Ivar Hartmann, pelas valiosas discussões na construção do trabalho e por nos ajudar com os dados do Supremo em Números; a Cecilia Machado, pela ajuda no manejo dos dados empíricos; e a Renan Medeiros de Oliveira pelo auxílio na preparação do manuscrito.

\section{Resumo}

Tribunais constitucionais com frequência se apresentam como instituições particularmente bem posicionadas para defender e promover direitos de minorias, incluindo a igualdade de gênero. No entanto, vieses de gênero e até discriminação por gênero podem ocorrer dentro dessas próprias instituições. Embora uma série de estudos empíricos já venha discutindo gênero como variável explicativa de decisões judiciais, estereótipos e hierarquias de gênero, também, podem influenciar o comportamento judicial para além do conteúdo das decisões - por exemplo, em como os juízes interagem entre si no processo decisório. Este artigo enfoca uma faceta desse fenômeno no âmbito do Supremo Tribunal Federal. Examinando um banco de dados com todas as decisões tomadas no plenário e nas turmas do tribunal entre 2001 e 2013, analisamos o impacto da variável gênero em duas dimensões do comportamento judicial em um ambiente colegiado. Mais especificamente, testamos se o gênero do(a) ministro(a) afeta o comportamento de seus(suas) colegas quando se trata de (i) divergir ou não do voto do relator; e (ii) pedir ou não vista dos autos. Nossos resultados apontam para um possível impacto do gênero nas atitudes dos juízes em relação a mulheres relatoras, em ao menos uma dessas duas dimensões. Quando o relator do caso é do sexo feminino, os outros juízes têm maior probabilidade de divergir do seu voto. Esses resultados sugerem que certos estereótipos de gênero - por exemplo, a ideia de que as mulheres são menos competentes ou confiáveis, e/ou menos capazes de retaliar - podem ajudar a explicar o comportamento dos juízes no STF e nos tribunais brasileiros em geral.

Palavras-chave: Supremo Tribunal Federal. Comportamento judicial. Processo decisório judicial. Votos vencidos. Pedidos de vista. Gênero. Discriminação. 


\section{Abstract}

Supreme Courts are generally portrayed as institutions particularly well-positioned to defend and promote rights of minorities, including gender rights. However, gender discrimination often occurs within these institutions. Although existing empirical studies have largely focused on how the gender of the judge affects his or her decisions on the merits of the case, gender hierarchy and gender stereotypes can have an impact in other aspects of Court's operation, such as in how judges relate to one another during deliberations. The paper aims to explore two facets of this phenomenon by looking at gendered relations in the Brazilian Supreme Court decision-making process. By examining a database containing all the court rulings debates between 2001 and 2013, we analyze the impact of gender in two key dimension of judicial behavior in a collegiate setting. More specifically, we test whether the gender of their colleagues affect how Brazilian Supreme Court Justices behaves when it comes to (i) dissenting from the case reporter's opinion; and (ii) asking for deliberations to be suspended, after the case reporter has spoken, in order to further study the arguments and case files. In both dimensions, we expect the justices' confidence in the reporter's or the dissenter's knowledge or authority on the issues being discussed plays an important role, which makes them relevant to understanding the role of gender stereotypes. Our preliminary results point to gender biases in the Justices' attitudes towards female case reporters and female dissenters in at least one of these dimensions: when the case reporter is female, the other Justices are more likely to dissent. We interpret these results as suggesting that gender stereotypes - for example, that women are less competent or reliable, and/ or less likely or less able to retaliate - might help us understand decision-making in the STF and in Brazilian courts more generally.

Keywords: Supreme Court. Constitutional court. Judicial behaviour. Judicial decision-making. Vista requests. Dissenting opinions. Brazil. Gender.

\section{INTRODUÇÃO}

Em maio de 2017, após um breve diálogo entre a ministra Rosa Weber e o ministro Luiz Fux, a presidente do Supremo Tribunal Federal (STF), ministra Cármen Lúcia, passou a palavra Weber para que lesse seu voto. O ministro Fux interveio, dirigindo-se à ministra Weber: "Concedo-lhe a palavra para [que você possa apresentar seu] voto integral”. A Presidente do Supremo Tribunal, Cármen Lúcia, respondeu:

Como concede a palavra? É a vez dela de votar. Ela é que concede, se quiser, a Vossa Excelência, um aparte. Foi feita agora uma análise, só um parêntese [...]. O número de vezes em que as mulheres são aparteadas [em tribunais constitucionais em que há mulheres] é 18 vezes maior do que entre os ministros [do sexo masculino]. [...] A ministra [Sonia] Sotomayor [da Suprema Corte dos EUA] me perguntou: "E lá [no Brasil], como é que é?" "Lá, em geral, eu e a ministra Rosa - não nos deixam falar. Então, nós não somos interrompidas". Mas agora é a vez da ministra Rosa, por direito constitucional, de votar. Tem a palavra, Ministra [Weber] $]^{1}$.

Essa não foi a primeira vez que a ministra Cármen Lúcia confrontou seus colegas do sexo masculino por questões de gênero². Em novembro de 2014, por exemplo, episódio semelhante ocorreu na discussão da constitucionalidade de uma lei que concedia às trabalhadoras o direito a um intervalo de 15 minutos antes de cumprir horas extras 3 . Argumentando pela inconstitucionalidade, o ministro Marco Aurélio afirmou: "se pudesse apontar um sexo forte, apontaria que é o feminino, mesmo porque, no lar, tenho um matriarcado,

1 STF. RE 612043, Pleno, Maio 10, 2017.

2 Para mais exemplos, ver GOMES, Juliana Cesario Alvim. O Supremo Tribunal Federal em uma perspectiva de gênero: mérito, acesso, representatividade e discurso. Direito \& Práxis, Rio de Janeiro, v. 7, n. 3, p. 652-676, jul./set. 2016.

3 STF. RE 658312, Pleno, 27 Novembro 2014. 
a começar pela Sandra, que é juíza, e juíza na área criminal!’. Posteriormente, a ministra Cármen Lúcia respondeu:

[...] na verdade, todo mundo é a favor dos direitos iguais das mulheres em público; à boca pequena, e seguramente na prática, os deboches, as brincadeiras continuam sendo uma demonstração de que estamos muito longe a chegar a uma igualdade substancial. [...] Ministro Marco Aurélio, somos, sim, o sexo frágil. Frágil em direitos, porque somos a maioria da população brasileira e temos muito menos direitos.

O ministro Marco Aurélio a interrompe: “É interessante: estou sob a sua presidência!". A ministra Cármen Lúcia, em seguida, acrescenta: "Mas eu estive, muitas vezes e com muita honra, sob a presidência por questão organizacional interna, apenas, e com absoluta tranquilidade".

Essas cenas soarão familiares para mulheres trabalhando em diferentes áreas e organizações. Tribunais constitucionais e cortes supremas, porém, com frequência, se apresentam como instituições particularmente bem posicionadas para defender e promover direitos de minorias em razão de seu papel contramajoritário, incluindo a igualdade de gênero e os direitos das mulheres. ${ }^{4}$ Assim, a ocorrência de discriminação de gênero dentro dessas instituições é particularmente preocupante - entre os próprios juízes, e mesmo quando o caso não envolve questões de gênero. Embora estudos empíricos venham enfocando o impacto do gênero como variável explicativa das decisões judiciais, estereótipos e hierarquias de gênero podem influenciar do comportamento judicial para além do conteúdo das decisões - como na forma pela qual os juízes se relacionam entre si como se dirigem aos seus colegas durante as deliberações.

Neste artigo, exploramos uma faceta desse fenômeno, examinando as relações de gênero ${ }^{5}$ entre ministros no processo decisório do Supremo Tribunal Federal. Examinando um banco de dados com todas as decisões tomadas no plenário e nas turmas do tribunal entre 2001 e 2013, analisamos o impacto da variável gênero em duas dimensões do comportamento judicial nos ambientes colegiados do STF. Mais especificamente, testamos se o gênero do(a) ministro(a) (masculino ou feminino) afeta o modo como seus(suas) colegas se comportam quando se trata de (i) divergir ou não do voto do relator; e (ii) pedir ou não vista dos autos.

Também investigamos se essas dinâmicas são afetadas por um ambiente no qual o comportamento de ministras do sexo feminino é influenciado pela presença de outras ministras (o que chamamos de "efeito de sororidade"), de duas maneiras diferentes: se elas são afetadas (a) pela presença de uma segunda ministra na composição do STF, e (b) pela presença de uma mulher na presidência do tribunal ou da turma, definindo a pauta e coordenando as deliberações.

Com base no desenho do processo decisório no STF, esperamos que o comportamento dos(as) ministros(as) seja influenciado, em todas essas dimensões, pela confiança que têm no conhecimento ou autoridade do relator sobre os assuntos em discussão. Nesse sentido, estereótipos de gênero podem influenciar comportamentos com relação a relatoras do sexo feminino. Isso pode ocorrer, por exemplo, devido a uma crença implícita de que as ministras são menos competentes ou menos confiáveis, ou à expectativa de que mulheres devem ser menos agressivas e mais colegiais e que, portanto, as juízas se sentiriam mais constrangidas em entrar em conflito com um colega do sexo masculino. Nossos resultados preliminares de fato apontam para vieses de gênero nas atitudes dos ministros em relação às relatoras. Quando o relator do caso é do sexo feminino, o restante do tribunal tem maior probabilidade de discordar do seu voto.

4 Uma recorrente justificativa para legitimar o poder de juízes não eleitos realizarem constitucionalidade de leis e atos normativos é a de que, pelo fato de seus integrantes não serem eleitos e contarem com uma série de garantias, Cortes Constitucionais poderiam e deveriam atuar de forma independente da vontade da maioria da população e, assim, a favor do direito de minorias incapazes de se defender adequadamente na arena política. Ver, por exemplo, BARROSO, Luís Roberto. Constituição, democracia e supremacia judicial: direito e política no Brasil contemporâneo. Revista da Faculdade de Direito-UERJ, v. 2, n. 21, jan./jun. 2012.

5 "As relações de gênero atravessam a sociedade, e seus sentidos e efeitos não estão restritos às mulheres. O gênero é, assim, um dos eixos centrais que organizam nossas experiências no mundo social. Onde há desigualdades que atendem a padrões de gênero, ficam definidas também posições relativas de mulheres e de homens — ainda que o gênero não o faça isoladamente, mas numa vinculação significativa com classe, raça e sexualidade". MIGUEL, Luís Felipe; BIROLI Flávia. Feminismo e política: uma introdução. São Paulo: Boitempo, 2014. p. 8. 
Embora as dimensões de análise sejam pontuais, elas fornecem insumos para um debate mais amplo com vistas a "expor as práticas e rituais, incentivos e hábitos, relacionamentos e normas culturais não verbalizadas tomados como certos" " que possam expressar e reforçar uma hierarquia de gênero dentro do STF e, talvez, para o judiciário e a comunidade jurídica como um todo. $\mathrm{Na}$ verdade, é possível que olhar para dinâmicas de gênero em um espaço judicial possa ajudar a revelar padrões presentes na sociedade brasileira de forma mais geral ${ }^{7}$.

\section{Gênero e tribunais no Brasil}

De um ponto de vista teórico, estudos de variados pontos de vista disciplinares têm destacado diferentes aspectos pelos quais o gênero influencia o funcionamento das instituições jurídicas: (i) a lei frequentemente impõe desvantagens às mulheres; (ii) o conteúdo dessa lei tem um viés "masculino", sendo construído por advogados e juízes do sexo masculino que impõem seus ideais, ainda que com suposta neutralidade e objetividade; (iii) a lei é uma "tecnologia de gênero", capaz de criar gênero em si. Esses insights fornecem úteis pontos de partida e hipóteses para estudos empíricos sobre como concepções, práticas e discursos de gênero podem ajudar a entender como o funcionamento do direito na prática.

Do ponto de vista empírico, apesar da centralidade que o STF desempenha na política brasileira, até muito recentemente o escopo da literatura sobre questões de gênero no tribunal se mostrava limitado. Abordagens mais tradicionais enfocam as discussões de mérito em casos envolvendo direitos das mulheres", enquanto trabalhos mais recentes têm procurado entender como o gênero pode impactar o funcionamento do tribunal, para além da substância de suas decisões. Nesse sentido, por exemplo, Gomes chama a atenção para os danos aos direitos das mulheres causados pelas dinâmicas internas, práticas, silêncios e discursos usados durante o processo de tomada de decisão pelos ministros, mesmo quando decidem casos em favor dessa minoria ${ }^{10}$; Annenberg examina o uso de estereótipos na fundamentação dos ministros em casos envolvendo gênero ${ }^{11}$; Machado e Bracarense investigam o papel desempenhado pelos movimentos de mulheres na promoção de sua agenda de direitos junto ao STF ${ }^{12}$.

Para além do STF, a literatura sobre tribunais e gênero no Brasil também incluiu temas como a aplicação da legislação sobre violência doméstica ${ }^{13}$ e violência de gênero ${ }^{14}$ nos tribunais nacionais. Especificamente so-

6 GUINIER, Lani; MINOW, Martha. Dynamism, not just diversity. Harvard Journal of Law \& Gender, Cambridge, v. 30, n. 2, p. 269-277, jun./nov. 2007.

7 Ver RESNIK, Judith. On the Bias: feminist reconsiderations of the aspirations for our judges. Southern California Law Review, Los Angeles, v. 61, n. 6, p. 1877-1944, Sep. 1988.

8 A frase foi tirada do título do livro de 1987 de Teresa de Lauretis “Technologies of gender: essays on theory, film and fiction”. 9 PIOVESAN, Flávia; GONÇALVES, Tamara Amoroso. Gênero no Supremo Tribunal Federal. In: SARMENTO, Daniel; SARLET, Ingo Wolfgang (Org.). Direitos fundamentais no Supremo Tribunal Federal: balanço e crítica. Rio de Janeiro: Lúmen Júris, 2011. p. 367-390.

10 GOMES, Juliana Cesario Alvim. O Supremo Tribunal Federal em uma perspectiva de gênero: mérito, acesso, representatividade e discurso. Direito es Práxis, Rio de Janeiro, v. 7, n. 3, p. 652-676, jul./set. 2016.

11 ANNENBERG, Flávia Xavier. Gender-based provisions in the united states and in brazil: tensions between the anti-stereotyping doctrine and the positive discrimination approach. Artigo inédito, 2017.

12 MACHADO, Marta Rodriguez de Assis; BRACARENSE, Ana Carolina. O caso do feto anencefálico: direitos sexuais e reprodutivos, confronto e negociação argumentativa no Supremo Tribunal Federal. Direito \& Práxis, Rio de Janeiro, v. 7, n. 3, p. 677-714, jul./set. 2016.

13 E.g., DIAS, Maria Berenice. A Lei Maria da Penha na Justiça: a efetividade da Lei 11.340/2006 de combate à violência doméstica e familiar contra a mulher. São Paulo: Revista dos Tribunais, 2007; FREITAS, Lúcia; LOIS, Cecilia Caballero. Acórdãos do STF sobre Lei Maria da Penha: Um estudo piloto da relação direito, gênero e linguagem. In: OLIVEIRA JUNIOR, José Alcebíades de; MENDES, Regina Lucia Teixeira; SCAMARELLA, Maria Luisa (Org.). Sociologia, Antropologia e Cultura jurídicas. Curitiba: CONPEDI/ UNICURITIBA, 2013. p. 247-265.

14 E.g., CASTILHO, Ela Wiecko Volkmer de. Criminalização do tráfico de mulheres: proteção das mulheres ou reforço da violência de gênero?. Cadernos Pagu, Campinas, n. 31, p. 101-123, jul./dez. 2008; PIMENTEL, Silvia; PANDJIARJIAN, Valeria; BEL- 
bre a estrutura interna e o funcionamento dos tribunais, os estudos existentes, em menor medida, discutem se as juízas femininas decidiriam de maneira diferente de seus colegas do sexo masculino ${ }^{15}$ e, principalmente, investigam os obstáculos à admissão e promoção de magistradas do sexo feminino ${ }^{16}$.

Com relação a esse último aspecto, vale observar que, entre 2002 e 2011, a proporção de mulheres admitidas na carreira judicial no Brasil aumentou. Durante esse período, as mulheres representaram 38,9\% de todos os novos juízes. No entanto, essa proporção caiu para 35,9\% entre 2012 e 2013. Em 2013, 42,8\% dos juízes substitutos eram mulheres, enquanto, nos tribunais de segunda instância e tribunais superiores, as mulheres representavam, respectivamente, $21,5 \%$ e $18 \%$ dos juízes. Vale notar que a maioria absoluta dessas mulheres é branca; apenas 15,2\% de todos os juízes no Brasil se declaram pardos, 1,5\% se declaram pretos e $1,4 \%$ nativos brasileiros ${ }^{17}$.

Em uma perspectiva regional, a participação feminina no judiciário brasileiro é baixa. Em 2016, entre 37 países do Caribe e da América Latina, o Brasil teve a quarta menor taxa de mulheres no tribunal de cúpula $(18,2 \%)^{18}$. Esse fenômeno não pode ser explicado por um número reduzido de mulheres nas profissões jurídicas (isto é, por um reduzido grupo de potenciais nomeadas para os tribunais superiores). Na realidade, 48\% dos mais de um milhão de membros da Ordem dos Advogados do Brasil são mulheres ${ }^{19}$; além disso, na população em geral, as mulheres tendem a ser mais educadas que os homens ${ }^{20}$. As raízes da disparidade de gênero no judiciário brasileiro ${ }^{21}$ parecem ser semelhantes a alguns padrões que Schultz identificou em outros países, especialmente a falta de conexões políticas necessárias para acessar posições importantes que só podem ser preenchidas por nomeação, bem como a imposição do ônus das responsabilidades domésticas às profissionais do sexo feminino. ${ }^{22}$

$\mathrm{Na}$ vasta literatura empírica nos EUA sobre comportamento judicial, problemas de gênero no funcionamento de tribunais vêm sendo explorados há muitos anos. A maioria desses trabalhos enfoca basicamente as mesmas duas questões: (1) o gênero do juiz faz com que seu comportamento ou decisão mude? (2) A presen-

LOQUE, Juliana. "Legítima defesa da honra", ilegítima impunidade de assassinos: um estudo crítico da legislação e jurisprudência da América Latina. In: CORRÊA, Mariza; SOUZA, Érica Renata (Org.). Vida em família: uma perspectiva comparativa sobre crimes de honra. Campinas: UNICAMP, 2006. p. 65-208.

15 SEVERI, Fabiana Cristina. O gênero da justiça e a problemática da efetivação dos direitos humanos das mulheres. Direito $e$ Práxis, Rio de Janeiro, v. 7, n. 1, p. 80-115 jan./mar. 2016; JUNQUEIRA, Eliane Botelho. Women in the Judiciary: a Perspective from Brazil. In: SCHULTZ, Ulrike; SHAW, Gisela (Org.). Women in the world's legal professions. Oxford: Hart, 2003; GREZZANA, Stefânia. Viés de Gênero no Tribunal Superior do Trabalho Brasileiro. 2011. 61f. Dissertação (Mestrado) - Escola de Economia de São Paulo, FGV, São Paulo, 2011.

16 E.g., SEVERI, Fabiana Cristina. O gênero da justiça e a problemática da efetivação dos direitos humanos das mulheres. Direito e Práxis, Rio de Janeiro, v. 7, n. 1, p. 80-115 jan./mar. 2016; BONELLI, Maria da Glória. Brazilian judges in-between professionalism, gender and difference. International Journal of the Legal Profession, v. 22, n. 2, p. 134-150, Apr. 2015; BONELLI, Maria da Glória. Profissionalismo, diferença e diversidade na advocacia e na magistratura paulistas. Revista Brasileira de Ciências Sociais, São Paulo, v. 28, n. 83, p. 125-140, out. 2013; FRAGALE FILHO, Roberto; MOREIRA, Rafaela Selem; SCIAMMARELLA, Ana Paula de O. Magistratura e gênero: um olhar sobre as mulheres nas cúpulas do judiciário brasileiro, 2015. Disponível em: <https://journals.openedition.org/ eces/1968>. Acesso em: 15 jun. 2016. SADEK, Maria Teresa. Magistrados: uma imagem em movimento. Rio de Janeiro: FGV, 2006.

17 CONSELHO NACIONAL DE JUSTIÇA. Censo do poder judiciário. Brasília: CNJ, 2014.

18 CEPAL. Judicial power: percentage of women judges in the highest court or Supreme Court < http://oig.cepal.org/en/indicators/judicial-power-percentage-women-judges-highest-court-or-supreme-court> Acesso em: 16 jul. 2018.

19 MIGALHAS. Dados da OAB mostram que quase metade dos advogados do país são mulheres, 2017. Disponível em: < http://www.migalhas.com.br/Quentes/17,MI265657,11049-Dados+da+OAB+mostram+que+quase+metade+dos + advogados + do + pais + sao $>$. Acesso em: 16 jul. 2018.

20 INSTITUTO BRASILEIRO DE GEOGRAFIA E ESTATÍSTICA. Estatísticas de gênero: uma análise do Censo Demográfico 2010. Rio de Janeiro: IBGE, 2014.

21 SMART, Carol. Las teorías feministas y el discurso jurídico. In: BIRGIN, Haidée et al (Org.). El derecho en el género y el género en el derecho. Buenos Aires: Biblos, 2000.

22 SCHULTZ, Ulrike; SHAW, Gisela (Org.). Women in the world's legal professions. Oxford: Hart, 2003; SEVERI, Fabiana Cristina. O gênero da justiça e a problemática da efetivação dos direitos humanos das mulheres. Direito e Práxis, Rio de Janeiro, v. 7, n. 1, p. 80115 jan./mar. 2016; BONELLI, Maria da Glória. Profissionalismo e diferença de gênero na magistratura paulista. Civitas: Revista de Ciências Sociais, Porto Alegre, v. 10, n. 3. p. 270-292, set./dez. 2010. BONELLI, Maria da Glória. Carreiras jurídicas e vida privada: interseções entre trabalho e família. Cadernos Pagu (UNICAMP), Campinas, n. 46, p. 245-277, jan./abr. 2016. 
ça de uma juíza no tribunal influencia o comportamento de seus colegas do sexo masculino? Nosso objetivo neste projeto é mais próximo dessa segunda vertente de análise. Investigamos o impacto do gênero no processo de decisão judicial além do conteúdo real de decisões e opiniões judiciais, incluindo comportamentos que ocorrem antes e durante as deliberações. Enfocamos o que poderia ser chamado de comportamento processual, colegial e deliberativo dos juízes, isto é, suas escolhas e ações dentro do funcionamento do maquinário da corte, independentemente de sua posição individual sobre o mérito de cada caso. Nosso objetivo é entender como o gênero afeta a maneira como os membros da corte se comportam em relação aos seus componentes do sexo feminino. ${ }^{23}$ Até que ponto os estereótipos e a discriminação de gênero explicam as atitudes judiciais de seus colegas no processo de tomada de decisão do STF? Como discutiremos na próxima seção, acreditamos que o STF é um ambiente institucional particularmente interessante para estudar essas questões.

\section{Gênero, colegialidade e julgamento no Supremo Tribunal Federal}

\subsection{Mulheres no STF ${ }^{24}$}

Desde sua criação em 1890 — ou desde 1824, se enfatizarmos a continuidade institucional com o Supremo Tribunal de Justiça do Império - , apenas três mulheres foram nomeadas para o Supremo Tribunal Federal. A primeira ministra mulher, Ellen Gracie, foi nomeada apenas em dezembro do ano 2000 e a segunda, Cármen Lúcia, em junho de 2006. A ministra Gracie presidiu o STF entre abril de 2006 e abril de 2008, quando a ministra Cármen Lúcia já fazia parte do tribunal. Em dezembro de 2011, a terceira mulher, a ministra Rosa Weber, foi indicada para preencher a vaga aberta pela aposentadoria da ministra Gracie. Em setembro de 2016, a ministra Cármen Lúcia se tornou presidente do Tribunal, cargo que ocupará até 2018.

Os caminhos dessas três ministras foram marcados por questões de gênero de muitas maneiras diferentes. Até a nomeação de Ellen Gracie em 2000, mulheres não podiam usar calças no prédio da Suprema Corte. Mas apenas em 2007 Cármen Lúcia se tornaria a primeira ministra a usá-las na sessão plenária do tribunal ${ }^{25}$. Na verdade, o gênero das ministras já influenciava como eram tratadas e percebidas mesmo antes de seu ingresso formal no tribunal, ainda no seu processo de nomeação ${ }^{26}$. Uma análise de suas sabatinas perante o Senado ilustra os obstáculos que enfrentaram. De fato, a maioria dos senadores, do sexo masculino, não pôde deixar de expressar, mesmo que às vezes implicitamente, seu desconforto com o fato de os nomeados serem mulheres. Apesar das diferenças nos três processos, em todos eles o gênero da ministra nomeada foi um "fantasma" na sala ${ }^{27}$.

23 Nesse sentido, nosso projeto se aproxima do trabalho pioneiro de Jacobi e Schweers sobre interrupções, durante os argumentos orais, na Suprema Corte dos EUA. Nesse artigo, os autores usam uma variedade de estratégias para tentar desvendar, explicando o que torna os juízes mais propensos a interromper um ao outro, os efeitos do gênero a partir dos efeitos da antiguidade e da ideologia. Na próxima fase deste projeto de pesquisa, esperamos poder responder questões semelhantes às de Jacobi e Schweers, incluindo qual é o papel do gênero na explicação de como os juízes interrompem uns aos outros durante as deliberações no STF. JACOBI, Tonja; SCHWEERS, Dylan. Justice. Interrupted: the effect of gender, ideology and seniority at Supreme Court oral arguments. Virginia Law Review, v. 103, p. 1379-1485, 2017.

24 Algumas das ideias desenvolvidas nesta seção foram previamente trabalhadas em GOMES, Juliana Cesario Alvim. O Supremo Tribunal Federal em uma perspectiva de gênero: mérito, acesso, representatividade e discurso. Direito \& Práxis, Rio de Janeiro, v. 7 , n. 3, p. 652-676, jul./set. 2016.

25 MINISTRA quebra tradição e usa calça no STF. 2007. Disponível em: <http://g1.globo.com/Noticias/Politica/0,MUL115655601,00-MINISTRA+QUEBRA+TRADICAO+E+USA+ CALCA+NO+STF.html>. Acesso em: 15 jul. 2018.

26 Analisando a sabatinas judiciais nos EUA, Sally J. Kenney chama atenção para o fato de que "as mulheres julgadoras enfrentaram mais duras sabatinas do que suas contrapartes masculinas; elas tiveram sua competência e objetividade mais frequentemente e descaradamente questionadas; e elas foram removidas do cargo em estados onde os ministros são rotineiramente mantidos. Estes são apenas alguns exemplos das maneiras pelas quais as mulheres experimentam preconceitos de gênero no sistema judicial" (tradução livre). KENNEY, Sally J. Gender \& Justice: Why women in the Judiciary really matter. New York: Routledge, 2013, p. 135-136.

27 Claude M. Steele em seu livro "Whistling Vivaldi: and other clues to how stereotypes affect us" se refere a estereótipos como 
Na sabatina da ministra Ellen Gracie, em 2000, os senadores a louvariam por ser a primeira mulher nomeada para a corte. Falaram sobre o que viam como "momento histórico", ao mesmo tempo em que faziam comentários tendenciosos de gênero. Um senador, por exemplo, incluiu o seguinte comentário em sua celebração da indicação de Gracie:

Adão estava dormindo, assim diz o Gênesis, foi retirada uma parte da costela de Adão, e Deus criou a mulher e disse que ambos formariam uma só carne. Então, eu acho que fomos nós, os homens, que desobedecemos ao Criador, e as mulheres, também, por sua timidez, talvez, ficaram muito tempo dedicadas aos afazeres domésticos e não participavam ativamente ${ }^{28}$.

Mais tarde, durante a sua confirmação como Presidente do Conselho Nacional de Justiça em 2006, a ministra Ellen Gracie foi submetida a comentários sexistas ainda mais sérios e explícitos "29: "O meu voto ainda leva em conta a beleza e o charme. Assim voto com muito prazer.", disse um senador; "Como ginecologista, aprendi a lidar de perto com as mulheres, a entender muito profundamente a sensibilidade feminina", disse outro. Um terceiro declarou que a ampla aceitação da nomeação da ministra se devia "à elegância física e moral, à dignidade e sobretudo à competência [da ministra]", e ainda outro acrescentou que Gracie estaria lá não para "ser sabatinada, mas [para ser] homenageada" 30 .

Como segunda mulher indicada ao STF — privando assim os senadores da oportunidade de celebrar o evento formal de sabatinar "a primeira mulher" —, o tratamento da ministra Cármen Lúcia foi diferente. Alguns senadores tentaram minimizar sua condição de gênero, enfatizando suas qualidades humanas e sua competência independentemente de seu gênero:

Para mim é indiferente e eu digo isso dissentindo da grande maioria que o Supremo Tribunal Federal seja composto por onze negros, ou onze brancos, ou por onze mulheres ou por onze homens. Me importa sim saber que lá estão onze magistrados ${ }^{31}$.

Por fim, durante o processo de nomeação da ministra Rosa Weber, o tópico mal foi levantado de forma explícita, na mesma tendência observada no caso de Carmen Lúcia. Uma das poucas exceções aconteceu quando uma senadora pediu sua opinião sobre a Lei Maria da Penha, acrescentando que Weber era uma fonte de orgulho e inspiração para ela e para as mulheres em geral.

Em geral, a questão de gênero no caso de Weber só ficou visível nas "entrelinhas" ${ }^{2}$. Alguns comentários dos senadores recorriam, implicitamente, a estereótipos. Um senador, por exemplo, comentou:

Sei que V. Ex é até exageradamente humilde, veio até aqui de preto. Quer dizer, poderia ter vindo com uma cor mais bonita; V. Exª é uma senhora bonita, respeitável. Parece que fez tudo para não se apresentar.

Além disso, em vez de fazer as perguntas típicas, para os padrões brasileiros, sobre a vida ou carreira do nomeado, ou mesmo sobre as controvérsias constitucionais da ordem do dia, os senadores se desdobraram

\footnotetext{
"fantasmas na sala" (2010).

28 COMISSÃO DE CONSTITUIÇÃO, JUSTIÇA E CIDADANIA. Ata da da $2^{a}$ Sessão Legislativa Extraordinária, da $51^{a}$ Legislatura, realizada em 21 novembro de 2000.

29 O Presidente do Conselho Nacional de Justiça, criado pela Emenda Constitucional n. 45/2004, é o atual presidente do Supremo Tribunal. Mesmo assim, a emenda constitucional exigia que cada novo presidente passasse por um processo de sabatina e confirmação perante o Senado. Este sistema foi modificado em 2009 (o presidente é, hoje, o único membro do Conselho Nacional de Justiça que não precisa ser sabatinado pelo Senado), e a ministra Gracie foi o último presidente do CNJ a passar pelo Senado antes de tomar posse.

30 MACHISMO marca sabatina de Ellen Gracie. 2006. Disponível em: <https://www1.folha.uol.com.br/fsp/ brasil/ fc2303200617.htm>. Acesso em: 16 jul. 2018.

31 COMISSÃO DE CONSTITUIÇÃO, JUSTIÇA E CIDADANIA. Ata da 11 a Reunião Ordinária, da $52^{a}$ Legislatura realizada em 10 de maio de 2006. Vale ressaltar que, ao contrário de seus pares do sexo masculino, as senadoras femininas enfatizaram o aspecto de gênero da nomeação.

32 A tensão em torno do gênero das mulheres nomeadas é "encoberta" por meio do tempo — talvez não visível, mas ainda assim parte da dinâmica. Em contraste com essa visão, no entanto, Araújo argumenta que podemos identificar um processo de "exclusão de gênero" à medida que mais mulheres são nomeadas (2015).
} 
para desafiar sua competência profissional e testar seu conhecimento legal. Por exemplo, um senador fez mais de vinte perguntas sobre diferentes áreas do Direito, sem interrupção, por mais de 20 minutos — o que nunca aconteceu a um homem indicado ao tribunal ${ }^{33}$.

Essas narrativas e anedotas, embora digam respeito ao comportamento de outras autoridades públicas (os senadores), sugerem ser provável que os estereótipos e a discriminação de gênero também desempenhem algum papel na maneira como os juízes do STF se relacionam com suas colegas do sexo feminino. A questão é onde e como exatamente procurar por essas dinâmicas dentro do processo decisório do tribunal. Discutiremos essas questões na próxima seção.

\subsection{Gênero e o papel do relator no processo decisório do STF}

O Supremo Tribunal cumpre, ao mesmo tempo, as funções de um tribunal constitucional, de uma corte de cassação (como instância máxima de decisão potencial sobre todos os recursos vindos de instâncias inferiores), de um tribunal de primeira instância em alguns dos procedimentos dentro de sua jurisdição ${ }^{34}$. Essa última função fornece ao STF a maior parte de sua vasta carga de trabalho. Nos últimos anos, o Tribunal recebeu uma média de mais de 60.000 novos casos anualmente. A grande maioria desses casos, no entanto, nunca é decidida pelo tribunal plenário ou pelas câmaras. Desde 1988, em média, mais de $95 \%$ das decisões no STF são tomadas por ministros individuais e suas equipes, embora os mecanismos exatos pelos quais os casos são filtrados, ainda, não tenham sido totalmente mapeados ${ }^{35}$.

Em todos esses papéis, nesse grande volume de processos, a figura do relator do processo é decisiva. Um dos ministros (excluindo o atual presidente) é aleatoriamente designado como relator quando um processo ingressa na pauta do tribunal ${ }^{36}$. O relator é responsável por administrar o caso dentro da burocracia interna do STF e tem poderes significativos antes que a turma ou o plenário possam se manifestar: pode dar decisões liminares em algumas circunstâncias; pode sumariamente rejeitar um recurso ou petição que seja "manifestamente infundada", ou que contradiga a jurisprudência estabelecida pelo tribunal; e, finalmente, compete ao relator decidir quando o caso está pronto para ser julgado por uma das instâncias de decisão coletiva do tribunal (turma ou plenário). O relator, portanto, tem poderes aparentemente absolutos de definição de pauta em relação ao caso ${ }^{37}$. Após a liberação do caso pelo relator, o presidente deve, então, colocá-lo

33 COMISSÃO DE CONSTITUIÇÃO, JUSTIÇA E CIDADANIA. Reunião Extraordinária da Comissão de Constituição, Justiça e Cidadania da $1^{a}$ Sessão Legislativa Ordinária da 54ª Legislatura, realizada, 64., 6 de dezembro de 2011.

34 FALCÃO, Joaquim; CERDEIRA, Pablo Camargo; ARGUELHES, Diego Werneck. I Relatório Supremo em números: o múltiplo Supremo. Rio de Janeiro: FGV, 2011; VIEIRA, Oscar Vilhena. "Supremocracia”. Revista Direito GV, São Paulo, v. 4, n. 2, p. 441-463, jul./dez. 2008.

35 Ver, por exemplo, VERÍSSIMO, Marcos Paulo. A Constituição de 1988, vinte anos depois: Suprema Corte e 'ativismo judicial à brasileira'. Revista Direito GV, São Paulo, v. 4, n. 2, p. 407-440, jul./dez. 2008. (discutindo um “writ of certiorari, no estilo brasileiro”). Ver também ROSEVEAR, Evan; HARTMANN, Ivar; ARGUELHES, Diego Werneck. Disagreement on the Brazilian Supreme Court. an exploratory analysis. 2015. Disponível em: <https://papers.ssrn.com/sol3/papers.cfm?abstract_id=2629329>. Acesso em: 16 jul. 2018, para uma discussão destes números e comparações com outros tribunais supremos e constitucionais; e ARGUELHES, Diego Werneck; RIBEIRO, Leandro Molhano. Ministrocracia: o Supremo Tribunal Individual no processo democrático brasileiro. Novos Estudos CEBRAP, v. 37, n. 1, p. 13-32, jan./abr. 2018.

36 Se o algoritmo que atribui os casos aos ministros é ou não verdadeiramente "aleatório", no sentido matemático tem sido um tema de debate na comunidade acadêmica brasileira (ver CHADA, Daniel; HARTMANN, Ivar. A distribuição de processos no Supremo é realmente aleatória?. 2016. Disponível em: <https://jota.info/colunas/supra/distribuicao-dos-processos-no-supremo-e-realmentealeatoria-25072016>. Acesso em: 15 jun. 2018. Em todo caso, porém, dado nosso atual conhecimento do sistema e do discurso oficial da Corte, assumimos que o mecanismo de designação de relatores não permite a alocação deliberada de um caso a um ministro específico.

37 ARGUELHES, Diego Werneck; RIBEIRO, Leandro Molhano. Ministrocracia: o Supremo Tribunal Individual no processo democrático brasileiro. Novos Estudos CEBRAP, v. 37, n. 1, p. 13-32, jan./abr. 2018. ARGUELHES, Diego Werneck; RIBEIRO, Leandro Molhano. 'The Court, it is I'? individual judicial powers in the Brazilian Supreme Court and their implications for constitutional theory. Global Constitutionalism, v. 7, n. 2, p. 236-262, 2018.; e FALCÃO, Joaquim; ARGUELHES, Diego Werneck. Onze supremos, todos contra o Plenário. In: FALCÃO, Joaquim; ARGUELHES, Diego Werneck; RECONDO, Felipe (Org.). Onz̧e supremos: o Supremo em 2016. Rio de Janeiro: FGV, 2017. p. 20-29. 
na pauta do Tribunal, fixando determinada data para que seu julgamento ocorra. Ambas as decisões — as do relator e da presidente — têm sido, na prática, totalmente discricionárias, não estando sujeitas a nenhum prazo relevante ${ }^{38}$.

O STF é um tribunal seriatim: formalmente falando, o processo de deliberação e decisão não resulta em um "voto do tribunal", mas apenas nos votos individuais dos ministros. ${ }^{39}$ Espera-se que o relator apresente um voto por escrito, que inclui um relatório dos principais fatos e histórico processual envolvendo o processo ("relatório"), bem como seus argumentos e decisão provisória para o caso ("voto"). Após o relator, os outros ministros seguem, em ordem de antiguidade reversa. O presidente é sempre o último a votar, além de ter o poder de dar o voto de minerva em algumas circunstâncias.

Por fim, vale notar que todas as deliberações no STF são públicas. Desde 2002, as deliberações no plenário são transmitidas ao vivo pelo canal oficial TV Justiça (e, desde 2006, também no canal oficial do YouTube). Em entrevistas, alguns ministros já mencionaram a ocorrência de reuniões informais, fechadas e pré-deliberações em alguns casos importantes. Contudo, há outros ministros, antigos e atuais, que alegam não ter participado de tais reuniões e/ou se opõem a tais práticas ${ }^{40}$.

\subsubsection{Votos vencidos e confiança no relator}

A vasta carga de trabalho do STF faz com que os ministros só consigam decidir, colegiadamente, uma fração do número total de $\operatorname{casos}^{41}$. Aproximadamente, 2000 casos por ano são decididos por uma das duas turmas de cinco juízes ou pelo plenário com todos os 11 magistrados presentes no caso. Mesmo essa fração do total de casos ainda é alta demais, na prática, para permitir análise e deliberação profundas por parte de todos os ministros em todos esses casos. Nesse cenário, os ministros devem escolher prioridades e selecionar quais casos merecem sua atenção total — não apenas dentre os processos de sua relatoria, mas também dentre os que estão com seus colegas. Com isso, espera-se que eles acabem confiando, de maneira geral, na posição do relator na maioria dos casos. Além disso, os ministros podem sentir que discordar uns dos outros, em uma sessão pública e sem preparação ou discussão interna prévias, pode fazê-los parecer mal aos olhos dos advogados presentes nas sessões e, talvez, mais significativamente, por quem esteja acompanhando o julgamento no YouTube ou na TV Justiça, no caso das sessões plenárias ${ }^{42}$.

Na prática, isso pode ajudar a explicar o alto nível de decisões unânimes no STF ${ }^{43}$. Nessas cerca de duas

38 ARGUELHES, Diego Werneck; HARTMANN; Ivar A. timing control without docket control: how individual justices shape the Brazilian Supreme Court's agenda. Journal of Law and Courts, Chicago, v. 5, n. 1, p. 105-140, mar./maio 2017; DIMOULIS, Dimitri; LUNARDI, Soraya. A tendência passivista do Supremo. In: FALCÃO, Joaquim; ARGUELHES, Diego Werneck; RECONDO, Felipe (Org.). O Supremo em 2015. Rio de Janeiro: FGV, 2016. p. 303-306.

39 MENDES, Conrado Hubner. O projeto de uma corte deliberativa. In: VOJVODIC, Adriana; PINTO, Henrique Motta; PAGANI, Rodrigo (Org.). Jurisdição constitucional no Brasil. São Paulo: Malheiros, 2012; MENDES, Conrado Hubner. The Supreme Federal Court of Brazil. In: JAKAB, András; DYEVRE, Arthur; ITZCOVICH, Giulio (Org.). Comparative constitutional reasoning. Nova York: Cambridge University Press, 2017.

40 Veja, por exemplo, as entrevistas para o projeto História Oral do Supremo Tribunal - especialmente as entrevistas dos ministros Carlos Velloso, Rafael Mayer, Nelson Jobim. FONTAINHA, Fernando et al. História Oral do Supremo Tribunal Federal. Rio de Janeiro: FGV, 2015-2016. Veja, em contraste, lamentando a ausência de tais encontros, as entrevistas com os juízes Cezar Peluso e Roberto Barroso. FONTAINHA, Fernando et al. História Oral do Supremo Tribunal Federal. Rio de Janeiro: FGV, 2015-2016.

41 FALCÃO, Joaquim; CERDEIRA, Pablo Camargo; ARGUELHES, Diego Werneck. O Supremo Tribunal Federal Processual. In: MARTINS, Ives Gandra S.; ROSSET, Patricia; AMARAL, Antonio Carlos R. (Org.). Estudos: Direito Público. Homenagem ao Ministro Carlos Mário da Silva Velloso. São Paulo: Lex Magister, 2013. p. 299-308.; SILVA, Virgílio Afonso da. O relator dá voz ao STF?: uma réplica a Almeida e Bogossian. Revista Estudos Institucionais, Rio de Janeiro, v. 2, n. 2, p. 648-669, 2016; VERÍSSIMO, Marcos Paulo. A Constituição de 1988, vinte anos depois: Suprema Corte e 'ativismo judicial à brasileira'. Revista Direito GV, São Paulo, v. 4, n. 2, p. 407-440, jul./dez. 2008.

42 SILVA, Virgílio Afonso da. Deciding without deliberating. International Journal of Constitutional Law, New York, v. 11, n. 3, p. 557-584, Jul. 2013.

43 Outra explicação adicional possível (e em contraste com o caso dos EUA) é a falta de "viés de seleção" no caso do Supremo Tribunal Federal. RIBEIRO, Leandro Molhano; ARGUELHES, Diego Werneck. Preferências, estratégias e motivações: pressupos- 
mil decisões colegiadas tomadas pelo tribunal a cada ano, em média, cerca de $93 \%$ são unânimes, enquanto 5,3\% tinham um único voto vencido (vale notar, porém, que essa média tem diminuído ao longo do tempo, desde os anos 90) ${ }^{44}$. Além disso, um estudo empírico constatou que, em relação a 692 decisões em Ações Diretas de Inconstitucionalidade (ADIs) decididas entre 1999 e 2006, o voto do relator correspondia à decisão final em 99\% dos casos ${ }^{45}$. Silva (2015), no entanto, relata que, em entrevistas anônimas, ministros atuais e antigos consideram a opinião do relator como "uma opinião como qualquer outra". ${ }^{46}$

A melhor maneira de compatibilizar esses dois tipos de achados contrastantes, como Silva observa, parece ser fazer uma distinção entre casos "fáceis" ou "rotineiros" (nos quais os juízes quase sempre se submetem ao relator e não investem muito tempo escrevendo suas próprias opiniões de antemão) e casos "difíceis" ou "importantes" (nos quais eles quase sempre chegam à sessão com suas opiniões plenamente desenvolvidas, ao invés de simplesmente confiarem no relator). ${ }^{47}$ Embora essa distinção seja insuficientemente teorizada nos estudos jurídicos existentes, parece plausível argumentar que, dadas as limitações de tempo e recursos com que os ministros operam, faria sentido supor que os ministros escolhem quais dos casos sob a responsabilidade de seus colegas são relevantes o suficiente para merecer o tempo e a atenção de seu gabinete.

Neste artigo, procuramos contribuir para explicar essas escolhas e comportamentos utilizando uma variável ainda não explorada pela literatura no caso do STF: gênero. Em estudo preliminar sobre as concordâncias na Suprema Corte dos Estados Unidos, Turner sugere que o tribunal

é um local antigo, de elite, conservador, no qual a presença relativamente recente de mulheres pode parecer perturbadora e os ministros que não estão habituados a serem deferentes às mulheres sentirão a necessidade de "corrigir" ou "esclarecer" uma opinião com a qual eles concordem mais nesses casos. ${ }^{48}$

De modo geral, acreditamos que o mesmo tipo de raciocínio é aplicável aos votos vencidos no STF. Entendemos que a propensão a divergir e o gênero estão conectados por meio do modo como os juízes percebem o papel do relator, e de como podem mudar especificamente seu comportamento quando o relator é do sexo feminino.

Operamos com a suposição de que divergir e/ou votar vencido no STF são ações minimamente custosas para o ministro que as adota ${ }^{49}$. Todo ministro tem a opção de simplesmente seguir a opinião do relator e

tos institucionais de teorias sobre comportamento judicial e sua transposição para o caso brasileiro. Direito e Práxis, Rio de Janeiro, v. 4, n. 7, p. 85-121, out./dez. 2013. O grande volume de casos, que pode em parte ser explicado pelo baixo custo dos recursos, torna improvável que os casos que chegam ao STF sejam necessariamente casos "difíceis". Ou seja, um grande número desses casos provavelmente tem soluções legais claras, simples e tecnicamente consensuais.

44 ROSEVEAR, Evan; HARTMANN, Ivar; ARGUELHES, Diego Werneck. Disagreement on the Brazilian Supreme Court. an exploratory analysis. 2015. Disponível em: <https://papers.ssrn.com/sol3/papers.cfm?abstract_id =2629329>. Acesso em: 16 jul. 2018.

45 OLIVEIRA, Fabiana Luci de. Supremo relator: processo decisório e mudanças na composição do STF nos governos FHC e Lula. Revista Brasileira de Ciências Sociais, São Paulo, v. 27, n. 80, p. 89-115, out. 2012 ("Em apenas 6 das 692 ações julgadas no período considerado, o voto do relator foi diferente do resultado final da decisão, ou seja, em $99 \%$ dos casos o voto do relator é igual à decisão final da corte. E como o relator é o primeiro a votar, isso implica que conhecer a direção desse voto é saber o resultado final em $99 \%$ das vezes.")

46 Para um importante debate em torno do papel do relator no processo de deliberação do STF, a partir do trabalho de SILVA, Virgílio Afonso da. 'Um Voto Qualquer?’: o papel do ministro relator na deliberação no Supremo Tribunal Federal. Revista de Estudos Institucionais, Rio de Janeiro, v. 1, n. 1, p. 180-200, 2015, ver ALMEIDA, Danilo; BOGOSSIAN, André. Nos termos do voto do relator: considerações acerca da fundamentação coletiva nos acórdãos do STF. Revista Estudos Institucionais, Rio de Janeiro, v. 2, n. 1, p. 263-297, 2016; SILVA, Virgílio Afonso da. O relator dá voz ao STF?: uma réplica a Almeida e Bogossian. Revista Estudos Institucionais, Rio de Janeiro, v. 2, n. 2, p. 648-669, 2016.

47 SILVA, Virgílio Afonso da. O relator dá voz ao STF?: uma réplica a Almeida e Bogossian. Revista Estudos Institucionais, Rio de Janeiro, v. 2, n. 2, p. 648-669, 2016.

48 TURNER, Charles C. Gender, judging, and the decision to concur: female justices and the Supreme Court. In: ENCONTRO ANNUAL DA "WESTERN POLITICAL SCIENCE ASSOCIATION", 2015, Las Vegas, Nevada, 2015.

49 EPSTEIN, Lee; LANDES, William; POSNER, Richard A. Why (and when) judges dissent: a theoretical and empirical analysis. Journal of Legal Analysis, Cambridge, v. 3, n. 1, p 101-137, mar. 2011; ROSEVEAR, Evan; HARTMANN, Ivar; ARGUELHES, Diego Werneck. Disagreement on the Brazilian Supreme Court. an exploratory analysis. 2015. Disponível em: <https://papers.ssrn.com/sol3/ 
declarar suas razões verbalmente; em vários casos, no processo decisório do STF, isso equivale, apenas, a dizer "sigo o relator". Se, de fato, os estereótipos de gênero e a discriminação estiverem em jogo na maneira como os juízes percebem os relatores, esperamos que os ministros estejam relativamente mais propensos a acatar a opinião de um relator do sexo masculino e simplesmente segui-la.

Com efeito, os ministros podem discordar com mais frequência quando o relator é do sexo feminino por dois tipos de razões. Primeiro, assumindo que os ministros se importam em chegar à decisão "correta", eles podem estar mais inclinados a discordar porque pensam que as juízas do sexo feminino são, de maneira geral, menos competentes, informadas e/ou confiáveis - isto é, eles sentem que podem ser levados a concordar com a decisão "errada" se confiarem demais em uma relatora mulher. Em segundo lugar, supondo que as deliberações no STF sejam parte de uma interação de longo prazo, baseada em colegialidade e respeito mútuo entre esses atores profissionais, um ministro pode achar que discordar de uma colega será menos custoso do que divergir de ministros do sexo masculino. Isto pode se dar devido à percepção de que, em razão dos arranjos de poder do tribunal, as mulheres terão menor possibilidade do que os homens de fazer prevalecer sua posição ou de exercer retaliações no futuro - tanto dentro do tribunal, como nos círculos sociais e profissionais mais amplos dos quais os ministros fazem parte. Com isso, mulheres seriam encaradas como alvos mais fáceis para desafios públicos ao seu conhecimento ou autoridade ${ }^{50}$.

\subsubsection{Interrompendo deliberações: pedidos de vista e confiança na opinião do relator}

Como em todos os outros tribunais no Brasil, uma vez iniciadas as deliberações no colegiado, qualquer juiz no STF pode pedir vista dos autos, suspendendo o julgamento para que os arquivos do caso sejam enviados ao seu gabinete para uma análise mais aprofundada. Pelo regimento interno do STF e pelas regras de direito processual vigente, o pedido de vista se justifica quando o ministro sente que não está suficientemente familiarizado com fatos ou argumentos do caso, e a duração da vista seria limitada a algumas semanas. Contudo, estudos recentes desconstruíram essa visão oficial sobre o uso do pedido de vista.

Usando o banco de dados do projeto Supremo em Números, um estudo revelou que (i) os pedidos de vista raramente são retornados dentro dos prazos oficiais - na verdade, sua duração média é de quase um ano e meio, ou cerca de 3 anos para vistas ainda não devolvidas quando o estudo foi realizado; (ii) não há casos de pedidos de vista fora do prazo sendo cancelados pelo tribunal plenário, o que indica que cada juiz tem, na prática, uma escolha livre acerca do momento em que permitirá que o caso retorne a julgamento ${ }^{51}$. Nesse cenário, os autores argumentam que os pedidos de vista devem ser interpretados como um poder de agenda negativo — uma espécie de veto - atribuído a cada um dos integrantes do tribunal, que podem, então, utilizá-lo para suspender as deliberações sobre casos ou temas que considere inconvenientes ou em contextos inoportunos ${ }^{52}$.

Como reconhecem os autores, porém, a falta de restrições formais ao uso de pedidos de vistas não exclui, necessariamente, que haja limites e custos informais associados ao uso dessa forma de controle da agenda

papers.cfm?abstract_id=2629329>. Acesso em: 16 jul. 2018.

50 Na literatura norte-americana sobre comportamento judicial e divergências, existem muitas teorias sobre os benefícios esperados que um ministro obtém ao divergir ou, pelo menos, ao ameaçar divergir. Por exemplo, a ameaça de abandonar uma coalizão de voto e adotar uma posição vencida ou concorrente pode permitir que obtenha algumas concessões daquela coalizão, sobretudo se ela representar o voto "majoritário" ou "da Corte". Ou, ainda, a possibilidade de atenção do público para um aspecto específico e controverso da decisão da maioria. Ver ROSEVEAR, Evan; HARTMANN, Ivar; ARGUELHES, Diego Werneck. Disagreement on the Brazilian Supreme Court. an exploratory analysis. 2015. Disponível em: < https://papers.ssrn.com/sol3/papers.cfm?abstract_ id=2629329 . . Acesso em: 16 jul. 2018. para uma discussão sobre a aplicabilidade de tais teorias ao caso brasileiro. Para os propósitos deste artigo, não vemos nenhuma razão clara para acreditar que os juízes esperariam obter benefícios diferentes com seus votos vencidos dependendo do gênero do relator.

51 ARGUELHES, Diego Werneck; HARTMANN; Ivar A. Timing control without docket control: how individual justices shape the Brazilian Supreme Court's agenda. Journal of Law and Courts, Chicago, v. 5, n. 1, p. 105-140, mar./maio 2017.

52 ARGUELHES, Diego Werneck; HARTMANN; Ivar A. Timing control without docket control: how individual justices shape the Brazilian Supreme Court's agenda. Journal of Law and Courts, Chicago, v. 5, n. 1, p. 105-140, mar./maio 2017. 
do Tribunal. De fato, se não houvesse nenhum custo para o uso dos pedidos de vista, qualquer ministro que sentisse estar em minoria poderia evitar, indefinidamente, qualquer derrota, em qualquer caso. $\mathrm{O}$ fato de o tribunal decidir tantos casos, sem que esse veto seja empregado na esmagadora maioria das deliberações, sugere que pode haver restrições informais no uso desse poder, ou custos associados ao seu emprego excessivo dentro do tribunal ${ }^{53}$.

Mais uma vez, como no caso de votos vencidos, podemos supor que há algum custo em usar esse poder, especialmente porque os juízes podem usar pedidos de vistas uns contra os outros, em retaliação a obstruções praticadas por seus colegas. Isso é verdade tanto em relação ao discurso oficial sobre pedidos de vista, quanto em relação à releitura feita pelos estudos mencionados acima. No primeiro caso, no uso "normal", as vistas apresentam um desafio à autoridade do relator do caso: o ministro pede vista quando acha que precisa de mais tempo para considerar os argumentos apresentados até agora, indicando que não deseja, simplesmente, confiar nos fatos e argumentos apresentados pelo relator sem uma análise mais detida. Em seu uso "estratégico", mapeado na literatura mencionada acima, os pedidos de vista bloqueiam uma decisão que o relator escolheu levar a tribunal e para a qual já havia preparado relatório e voto.

Estas são, portanto, as hipóteses que informam nosso estudo: esperamos que uma dinâmica de gênero seja perceptível no comportamento judicial no STF tanto quanto aos pedidos de vista, quanto às divergências com o relator. Relatoras do sexo feminino deveriam aumentar a probabilidade de ocorrência tanto de votos vencidos, quanto de pedidos de vista. Essas hipóteses se ancoram em duas teorias possíveis e não excludentes sobre o comportamento judicial nessas dimensões.

Em primeiro lugar, se mulheres forem consideradas menos competentes ou confiáveis como relatoras por seus pares em razão de seu gênero, relatoras do sexo feminino aumentariam a probabilidade de pedidos de vista por juízes que, nessa narrativa estereotipada, sentiriam menos confiança no trabalho da relatora em explicar as controvérsias envolvidas no caso e em oferecer a melhor solução. Aqui, o gênero interage com deferência à competência ou conhecimento do relator.

Em segundo lugar, o gênero, também, pode interagir com a colegialidade, entendida aqui como o conjunto de relações de reciprocidade, minimamente cordiais e profissionais, que membros de um órgão judicial coletivo devem desenvolver e manter uns com os outros ao longo do tempo. Os custos esperados de bloquear uma decisão por uma relatora do sexo feminino devem ser menores se as mulheres forem de fato consideradas menos poderosas que os homens no tribunal, e, por isso, tiverem menos propensão a impor seu posicionamento ou retaliar do que suas contrapartes masculinas. Esses dois conjuntos de motivos não são excludentes, e ambos nos levam a supor que os juízes terão maior probabilidade de usar vistas para interromper e impedir decisões quando o relator for do sexo feminino.

\section{Metodologia de Pesquisa e Resultados}

\subsection{Dados e Estratégia Empírica}

Com base nas teorias discutidas na seção anterior, testamos se o gênero do relator influencia a probabilidade de (i) algum ministro pedir vista e ii) algum ministro votar vencido (isto é, a probabilidade de a decisão ser ou não unânime). Também investigamos se o gênero aumenta (iii) a chance de haver divergência, expressa no número de votos vencidos, nos casos não unânimes. Além disso, procuramos dar alguns passos preliminares para investigar se tais efeitos são amplificados ou não quando há mais de uma mulher no tribunal

53 ARGUELHES, Diego Werneck; HARTMANN; Ivar A. Timing control without docket control: how individual justices shape the Brazilian Supreme Court's agenda. Journal of Law and Courts, Chicago, v. 5, n. 1, p. 105-140, mar./maio 2017. 
("efeito de sororidade") e, em particular, quando a presidente do Supremo é uma mulher. A essa variedade do "efeito sororidade", chamaremos "Efeito Ellen Gracie". A ministra Ellen Gracie foi a primeira presidente mulher do STF, e foi a única mulher presidente no período abrangido por nossos dados até agora.

Os dados utilizados neste trabalho são provenientes do projeto Supremo em Números, da FGV Direito Rio, banco de dados com mais de 1,8 milhão de ações judiciais do STF, entre 1988 e 2016. A amostra deste trabalho abrange um período de janeiro de 2001 a dezembro de 2013, resultando em uma amostra de 1.034 processos, selecionados por meio de amostragem aleatória estratificada com um único estágio. A amostra utilizada é composta por diversas variáveis, como o número do processo no sistema interno de gestão de processos do STF, o nome do relator, os nomes do autor da ação e do réu, o número de vistas solicitadas pelos magistrados, a data de arquivamento, a data do parecer produzido pelo Ministério Público etc.

Nossa especificação para medir o efeito de gênero do relator é:

$$
\text { Yit }=\beta 0+\beta 1 \text { Gêneroi }+\beta 2 \text { D_Anoi }+\beta 3 \text { D_Sororidadeit }+\beta 4 \text { D_EllenGracieit }+ \text { sit }
$$

Em que Yit é um resultado do processo i (número de vistas, decisão unânime e dissidência) no tempo t. Gênero é uma variável dummy ${ }^{54}$ (gênero do relator do processo). Gênero é igual a 1 se for do sexo feminino e a 0 caso contrário. D_Ano é um conjunto de efeitos fixos de ano que considera possíveis efeitos de tempo comuns entre os processos. D_Sororidade é uma variável dummy que explica a presença de mais de uma ministra no STF (quando há mais de uma ministra a variável assume valor igual 1 - e assume valor $0 \mathrm{em}$ caso contrário). D_EllenGracie é outra variável dummy que responde por Ellen Gracie como presidente do STF. A variável sit é o termo de erro.

\subsection{Resultados Preliminares}

Os resultados da Eq. (1) estão apresentados na Tabela 1.

Tabela 1 - Efeito de gênero no STF: pedido de vista.

Tabela 1

Efeito de Gênero no STF

\begin{tabular}{|c|c|c|c|c|c|c|c|}
\hline \multicolumn{8}{|c|}{ Pedido de Vista } \\
\hline & (1) & (2) & (3) & (4) & (5) & (6) & (7) \\
\hline & \multicolumn{4}{|c|}{ Todos } & Plenário & 1a Turma & $2 \pm$ Turma \\
\hline Relatora mulher & $0,02(0,02)$ & $0,02(0,02)$ & $0,01(0,02)$ & $0,01(0,02)$ & $0,02(0,06)$ & $-0,0(0,02)$ & $0,01(0,04)$ \\
\hline Sororidade & $\mathrm{N}$ & $\mathrm{Y}$ & $\mathrm{Y}$ & $Y$ & $\mathrm{Y}$ & $\mathrm{Y}$ & $Y$ \\
\hline Efeito Ano & $\mathrm{N}$ & $\mathrm{N}$ & $Y$ & $Y$ & $\mathrm{Y}$ & $\mathrm{Y}$ & $\mathrm{Y}$ \\
\hline Efeito Ellen & $\mathrm{N}$ & $\mathrm{N}$ & $\mathrm{N}$ & $\mathrm{Y}$ & $Y$ & $\mathrm{Y}$ & $\mathrm{Y}$ \\
\hline Constante & 0,03 & 0,03 & 0,02 & 0,02 & 0,13 & 0 & 0,04 \\
\hline
\end{tabular}

Os resultados das Colunas (1) - (4) são para plenário, primeira e segunda turma juntos. A coluna (1) relata o resultado de uma regressão via Método dos Mínimos Quadrados Ordinários ${ }^{55}$ (MQO) para o número de

54 Uma variável dummy é uma variável binária, cujo caso mais simples ocorre quando fazemos a variável igual a 1 para uma categoria e 0 para a categoria mutuamente exclusiva à primeira. Uma variável de gênero é uma dummy, pois assume valor igual a 1 se for do sexo feminino e 0 caso seja do sexo masculino.

55 O Método dos Mínimos Quadrados Ordinários é uma técnica de otimização matemática que procura encontrar o melhor ajuste para um conjunto de dados tentando minimizar a soma dos quadrados das diferenças entre o valor estimado e os dados observados (tais diferenças são chamadas "resíduos"). Para maiores informações, ver GUJARATI, D. N. Basic econometrics. Tata McGraw-Hill Education, 2009. 
pedidos de vista sem quaisquer controles. Coluna (2) inclui o controle efeito "Sororidade"; Coluna (3) inclui efeitos fixos de ano; e Coluna (4) inclui efeito "Ellen Gracie". Independentemente da especificação, os resultados mostram que o gênero do relator não afeta a probabilidade de pedido de vista. Os resultados não mudam quando consideramos, apenas, as decisões tomadas pelo plenário, primeira turma e segunda turma, expostos na Coluna (5), Coluna (6) e Coluna (7), respectivamente.

Tabela 2 - Efeito de gênero no STF: divergência.

Tabela 2

\section{Efeito de Gênero no STF}

\begin{tabular}{|c|c|c|c|c|c|c|c|}
\hline \multicolumn{8}{|c|}{ Divergência } \\
\hline & (1) & $(2)$ & (3) & (4) & (5) & (6) & (7) \\
\hline & \multicolumn{4}{|c|}{ Todos } & Plenário & 1a Turma & 2a Turma \\
\hline Relatora mulher & $0,19^{* *}$ & $0,17^{*}$ & $0,19^{*}$ & $0,19^{*}$ & $0,32^{* * *}$ & 0,08 & 0,55 \\
\hline Sororidade & $\mathrm{N}$ & Y & Y & Y & Y & Y & Y \\
\hline Efeito Ano & $\mathrm{N}$ & $\mathrm{N}$ & $\mathrm{Y}$ & $\mathrm{Y}$ & Y & Y & $\mathrm{Y}$ \\
\hline Efeito Ellen & $\mathrm{N}$ & $\mathrm{N}$ & $\mathrm{N}$ & Y & Y & Y & $\mathrm{Y}$ \\
\hline Constante & $-0,15$ & $-0,18$ & $-0,35$ & $-0,35$ & $-0,11$ & $-0,14$ & $-0,25$ \\
\hline
\end{tabular}

$\mathrm{N}=1034$

A Tabela 2 reporta os resultados da Eq. (1) com a variável dependente "divergência". A fim de estimar o impacto de gênero na probabilidade de voto vencido dos ministros, precisamos usar uma outra distribuição de erros, já que, dado o tamanho da corte (11 juízes), a variável "divergências" somente pode assumir 6 valores possíveis ( 0 votos vencidos, 1 voto vencido, 2 votos vencidos, 5 votos vencidos).

A coluna (1) relata o resultado de uma regressão de $\operatorname{Poisson}^{56}$ para votos vencidos sem controles. Os resultados da Tabela 2 revelam que, independentemente dos controles adotados, o efeito de gênero nos votos vencidos é positivo e significativo, ou seja, se o relator é do sexo feminino, há uma maior probabilidade de votos divergentes.

Para saber em que medida o gênero (feminino) do relator aumenta a probabilidade de os ministros votarem vencidos, precisamos fazer a seguinte conta:

$$
\exp (0,19)=1,20
$$

Ou seja, a taxa de divergência para relatoras do sexo feminino é 1,2 vez maior do que para os relatores do sexo masculino.

A coluna (5) da Tabela 2 apresenta o resultado apenas do plenário. Nesse caso, o efeito de gênero é, ainda, maior e mais significativo. A taxa de divergência para uma relatora mulher é 1,37 vez maior do que para o relator homem. Os resultados para a primeira e a segunda turmas não são significativos, o que pode ser explicado pela baixa representatividade de mulheres. Se há uma mulher na primeira turma, então (com exceção de alguns períodos) não haverá mulher na segunda turma, e vice-versa.

Ao tentarmos abordar a mesma questão — relatoria feminina aumenta a probabilidade de divergências — de um ângulo diferente, chegamos à Tabela 3, que reporta os resultados da Eq. (1) com "unanimidade"

56 Em estatística, regressão de Poisson é uma forma de análise de regressão usada para modelar contagem de dados e tabelas de contingência. Regressão de Poisson assume a variável resposta Y como uma distribuição de Poisson, e assume que o logaritmo de seu valor esperado pode ser modelado por uma combinação linear de parâmetros desconhecidos. Ver, por exemplo, CASELLA, George; BERGER, Roger L. Statistical inference. 5. ed. Belmont: Duxbury, 2002. 
(ou seja, se o resultado da decisão foi uma decisão unânime ou não unânime) como variável dependente. A coluna (1) relata os resultados de uma regressão MQO para unanimidade, sem controles.

Tabela 3 - Efeito de gênero no STF: unanimidade.

Tabela 3

\section{Efeito de Gênero no STF}

\section{Unanimidade}

\begin{tabular}{|c|c|c|c|c|c|c|c|}
\hline & (1) & (2) & (3) & (4) & (5) & (6) & (7) \\
\hline & \multicolumn{4}{|c|}{ Todos } & Plenário & $1^{12}$ Turma & $2^{2}$ Turma \\
\hline Relatora mulher & $-0,06^{*}$ & $-0,07^{*}$ & $-0,04$ & $-0,04$ & $-0,33^{* * *}$ & 0,06 & 0,02 \\
\hline Sororidade & $\mathrm{N}$ & Y & $\mathrm{Y}$ & $\mathrm{Y}$ & Y & $\mathrm{Y}$ & $\mathrm{Y}$ \\
\hline Efeito Ano & $\mathrm{N}$ & $\mathrm{N}$ & $Y$ & Y & $\mathrm{Y}$ & $\mathrm{Y}$ & $\mathrm{Y}$ \\
\hline Efeito Ellen & $\mathrm{N}$ & $\mathrm{N}$ & $\mathrm{N}$ & Y & $Y$ & $\mathrm{Y}$ & $\mathrm{Y}$ \\
\hline Constante & 0,84 & 0,85 & 0,86 & 0,86 & 0,45 & 0,99 & 0,72 \\
\hline
\end{tabular}

$\mathrm{N}=1034$

Os resultados da Tabela 3 revelam que, quando adicionamos todos os controles, como mostrado na coluna (4), o impacto do gênero na unanimidade de votos não é significativo. No entanto, quando olhamos, apenas, para os casos decididos pelo plenário, os resultados revelam que, quando o relator é do sexo feminino, a chance de unanimidade diminui $0,73 \%$ com significância de $1 \%$. Os resultados para a primeira e segunda turma não são significativos.

Em resumo, a partir dos dados coletados, nossos resultados sugerem que os relatores femininos tendem a atrair 1,2 vez mais votos vencidos do que os relatores masculinos, efeito aumenta para 1,37 quando consideramos apenas o tribunal pleno. Com relação aos pedidos de vista, com nossos dados atuais, no entanto, não fomos capazes de encontrar nenhum resultado estatisticamente significativo.

\section{ESTEREÓtIPO dE GÊNERO E dISCUSSÃo dOS RESULTADOS}

As teorias mais influentes sobre gênero e poder têm enfatizado o papel central dos estereótipos de gênero explicando a sub-representação de mulheres em cargos de liderança. ${ }^{57}$ Por um lado, diversas teorias enfatizam como crenças sobre semelhanças e diferenças entre os sexos fazem com que as pessoas tendam a ver as mulheres como menos qualificadas para esse tipo de cargo do que os homens. Por outro, crenças normativas das pessoas sobre como homens e mulheres deveriam agir fazem com que mulheres que não ajam de maneira compatível com o estereótipo "feminino" sejam classificadas como desagradáveis, indignas de recompensas organizacionais, e até sujeitas a penalidades sociais e econômicas.

Experimentos mostram a existência de bias desfavoráveis às mulheres que impedem que sua competência seja identificada. Experimento realizado em 2012, nos Estados Unidos, contatou que, mesmo apresentando candidaturas idênticas, candidatos homens eram considerados por cientistas homens e mulheres mais competentes e mais adequados para vagas de gerente de laboratório científico do que as contrapartes femininas,

57 Por exemplo: EAGLY, Alice; CARLI, Linda L. Women and the labyrinth of leadership. Harvard Business Review, Cambridge, v. 85, n. 9, p. 62-67, Sep. 2007; MOSS-RACUSIN, Corinne. A.; RUDMAN, Laurie. A. Disruptions in women's self-promotion: the backlash avoidance model. Psychology of Women Quarterly, Piscataway, v. 34, n. 2, p. 186-202, apr./jun. 2010. 
além de receberem ofertas de salário $\$ 4,000$ maiores e outras vantagens ${ }^{58}$ Em outro estudo, pesquisadores concluíram que empregadores, quando tinham conhecimento do sexo do candidato, tendiam a contratar duas vezes mais homens do que mulheres com base em uma tarefa aritmética que homens e mulheres, na média, desempenham de maneira igual. ${ }^{59}$

Como se vê nos casos elencados acima, a condutas dos empregadores, ao avaliar o melhor candidato para uma vaga, frequentemente não se baseia em uma escolha racional. O que mostra a literatura é que, nesse processo, os estereótipos de gênero têm um papel central. Estereótipos de gênero são generalizações acerca das diferenças entre homens e mulheres que pressupõe que (i) essa diferença existe; (ii) é relevante e relativamente fixa; e (iii) envolve uma série de características, como, por exemplo, uma inclinação feminina para questões domésticas. ${ }^{60}$

Estereótipos, com relação às mulheres, podem se manifestar tanto de maneira hostil quanto de maneira benevolente. No primeiro caso, se materializam como "ressentimento em relação a mulheres percebidas como querendo controlar homens". No segundo, quando as mulheres são tratadas como "criaturas frágeis". Em qualquer uma de suas manifestações, estereótipos causam danos aos indivíduos que, ora se vêem pressionados a se conformarem, ora são punidos por não o fazerem. Como ressaltem Peter Glick e Susan T. Fiske, estereótipos não são

meramente descritivos, mas prescritivos, por que um funcionamento social eficiente requer que os indivíduos sejam socializados para possuir os traços requeridos para uma performance bem-sucedida do papel que desemprenha no grupo. ${ }^{61}$

$\mathrm{Na}$ medida em que cargos de gerência e de chefia são vistos como cargos masculinos, a "discriminação ocorre quando os avaliadores parte do pressuposto de que homens mais do que mulheres possuem esses traços estereotipicamente masculinos". ${ }^{62}$ Do mesmo modo, a maneira por meio da qual as características são percebidas é influenciada pelos estereótipos de gênero. Por exemplo, “o mesmo comportamento pode ser descrito como 'muito assertivo' para uma mulher e ‘não muito assertivo' para um homem”. ${ }^{63}$ Além disso, em avaliações subjetivas, o critério considerado mais importante para o desempenho da profissão pode ser alterado, subjetivamente, para justificar discriminação contra mulheres. Avaliando candidatos para o cargo de chefe de polícia, por exemplo, participantes de um estudo mudaram o critério que consideravam o mais importante para o desempenho da profissão — de educação formal para "malandragem da rua" (streetwise) — de forma a beneficiar o candidato do sexo masculino. ${ }^{64}$

Além dos estereótipos, dois outros fatores influenciam as dinâmicas de gênero em ambientes de trabalho e impactam diretamente na divisão de poderes nesses espaços. Um deles é a existência de redes de relaciona-

58 MOSS-RACUSIN, Corinne A. Science faculty's subtle gender biases favor male students. Proceedings of the National Academy of Sciences, v. 109, n. 41, p. 16474-16479, 2012.

59 REUBEN, Ernesto; SAPIENZA, Paola; ZINGALES, Luigi. How stereotypes impair women's careers in science. Proceedings of the National Academy of Sciences, v. 111, n. 12, p. 4403-4408, 2014.

60 SCHULTZ, Vicki. Telling stories about women and work: judicial interpretations of sex segregation in the workplace in Title VII cases raising the lack of interest defense. Harvard Law Review, v. 103, p. 1749-1843, 1990.

61 E continuam os autores: "Assim, mulheres são punidas quando violam a prescrição de serem afetuosas ou agregativas. Atos de autopromoção ou assertividade por parte de mulheres são punidos por irem de encontro a ideias de agradabilidade feminina, são fortemente desgostados e podem gerar discriminação para contratação ou promoção. Em contraste, não é particularmente esperado que homens sejam agradáveis (e definitivamente é esperado que sejam assertivos), eles não são punidos por esse tipo de comportamento. Normas prescritivas de gênero criam um dilema para as mulheres no trabalho na medida em que trilham a fina linha entre exibir traços estereotipicamente masculinos que são geralmente associados com o mundo do trabalho e aparentarem não serem assertivas (e logo, não agradáveis)". GLICK, Peter; FISKE, Susan T. Sex discrimination: the psychological approach. In: CROSBY, Faye et al (Ed.). Sex discrimination in the workplace: multidisciplinary perspectives. Malden, MA: Blackwell, 2007. p. 162.

62 GLICK, Peter; FISKE, Susan T. Sex discrimination: the psychological approach. In: CROSBY, Faye et al (Ed.). Sex discrimination in the workplace: multidisciplinary perspectives. Malden, MA: Blackwell, 2007. p. 16.

63 GLICK, Peter; FISKE, Susan T. Sex discrimination: the psychological approach. In: CROSBY, Faye et al (Ed.). Sex discrimination in the workplace: multidisciplinary perspectives. Malden, MA: Blackwell, 2007. p. 167-168.

64 GLICK, Peter; FISKE, Susan T. Sex discrimination: the psychological approach. In: CROSBY, Faye et al (Ed.). Sex discrimination in the workplace: multidisciplinary perspectives. Malden, MA: Blackwell, 2007. p. 168-169. 
mento (networking) que surgem e se desenvolvem marcadas por características de sociabilidade masculina. Trata-se de redes que se desenvolvem fora do ambiente de trabalho, em atividades que tradicionalmente excluem as mulheres. Estudos sugerem que homens e mulheres tendem a desenvolver redes de relacionamento homofílicas (ou seja, com pessoas do mesmo sexo ${ }^{65}$ ) contudo, homens tenderiam a se beneficiar de tal fato por estarem tradicionalmente presentes em maior número em posições hierarquicamente superiores.

Um terceiro fator, de estrema relevância tanto para as dinâmicas de gênero em ambientes de trabalho, é a questão do assédio. O assédio está relacionado a uma estratégia masculina de ativamente excluir as mulheres de certos ambientes de trabalho como forma de não perder seu status e/ou identidade. $\mathrm{O}$ assédio não se limita a "fazer da mulher o objeto de sua atenção sexual", mas abrange um amplo rol de atividades que "minam a confiança [da mulher] e a [sua] imagem como uma trabalhadora capaz". ${ }^{66}$

Na prática, o assédio funciona como "um guardião do gênero" por meio da corrosão da capacidade das mulheres de exercerem um trabalho satisfatório, ao mesmo tempo em que "policia as fronteiras do trabalho e protege a imagem masculina idealizada, assim como a identidade daqueles que o praticam". ${ }^{67}$

Esses achados, embora resultantes de pesquisas realizadas em outros contextos, são um pano de fundo importante para a leitura dos resultados deste trabalho. Na seção anterior, mostramos que há maior divergência no STF quando mulheres são relatoras. Uma primeira explicação seria simplesmente o fato de que mulheres (seja no geral, sejam as que estavam no STF no período analisado) são "piores", como relatoras, do que os homens, o que explicaria seu menor sucesso, nessa posição, do que seus pares masculinos.

No entanto, a literatura já mencionada, bem como as pesquisas indicadas nos parágrafos anteriores, nos leva a crer resultados como os que obtivemos neste trabalho pedem explicações alternativas para essa diferença de gênero no caso das divergências no STF.

Além da adesão a certos estereótipos relativos à incompetência e à falta de conhecimento, a divisão de poderes dentro do tribunal decorrente desses estereótipos (que fariam com o que as mulheres tivessem menor poder para fazer valer suas posições e para retaliar) são úteis para explicar o elevado índice de divergência 1.2 (e 1.37 no plenário) maior quando a relatora é mulher.

\section{Considerações finais}

Estereótipos de gênero e discriminação (bem como as dinâmicas de poder que deles advém) podem impactar o comportamento judicial e a dinâmica dos tribunais de muitas maneiras diferentes. Neste artigo, nos propusemos a usar o gênero para explicar como os ministros se relacionam entre si no mais alto tribunal do Brasil, o Supremo Tribunal Federal. O STF é um cenário particularmente útil para discutir o impacto do gênero no comportamento judicial, além da real posição substantiva dos ministros sobre os méritos de um caso. Devido à grande carga de trabalho do tribunal, os juízes somente podem concentrar sua atenção em um número muito limitado de ações judiciais. Nesse cenário, a literatura existente sugere que o papel do

65 TORRES, Lise; HUFFMAN, Matt L. Social networks and job search outcomes among male and female professional, technical, and managerial workers. Sociological Focus, v. 35, n. 1, 2002.

66 SCHULTZ, Vicki. Reconceptualizing sexual harassment. Yale Law Journal, v. 107, p. 1687, 1998. Entre tais práticas, Vicky Schultz enumera: "caracterizar o trabalho apenas como sendo apropriado para homens; depreciar a performance ou habilidade das mulheres ao executarem o trabalho; prover formas benevolentes de ajuda para a execução do trabalho; reter informação, treinamento ou oportunidades de aprender a fazer bem o trabalho; promover sabotagem deliberada do trabalho; oferecer avaliações sexistas relativas à performance das mulheres ou negar promoções merecidas, isolar mulheres de redes sociais (networking) que conferem um sentido de pertencimento, negar às mulheres os prerequisitos ou privilégios requeridos para o sucesso; designar às mulheres tarefas fora das atribuições do trabalho em razão de estereótipos de gênero (como realizar a limpeza ou servir café); pregar peças, insultar ou realizar outras formas de maus-tratos com intuito de lembrar às mulheres que elas são diferentes e estão fora do lugar, e fisicamente investir ou ameaçar as mulheres que ousarem reagir". Loc. cit.

67 SCHULTZ, Vicki. Reconceptualizing sexual harassment. Yale Law Journal, v. 107, p. 1691, 1998. 
relator se torna crucial na explicação de padrões de tomada de decisão no STF em um grande número de casos, já que os ministros não teriam escolha de se dedicar à informação, expertise e argumentos trazidos na sessão pelo relator nos casos que eles não consideram particularmente relevantes, complexos ou delicados.

Se isso é verdade, então, as expectativas de gênero podem moldar como os outros juízes se comportam em relação aos relatores em um grande número de casos. De fato, nossos resultados neste artigo sugerem que os relatores femininos tendem a atrair 1.2 vezes mais votos vencidos do que os relatores masculinos. Isso pode ser explicado tanto pela percepção enviesada de que as ministras são menos confiáveis e/ou competentes que suas contrapartes masculinas, quanto pela possibilidade de serem percebidas como menos propensas a fazer valer seu posicionamento e/ou retaliar (divergindo mais no futuro, por exemplo) contra seus pares, que se veriam, portanto, mais encorajados a discordar publicamente de relatoras do que de relatores. Esse efeito aumenta para 1.37 quando consideramos, apenas, o tribunal pleno. As deliberações no STF são sempre públicas, mas apenas no plenário são transmitidas ao vivo pela TV Justiça. Isso pode sugerir que pode haver uma conexão entre o comportamento de gênero em relação ao relator e o aumento da exposição, e percepção de relevância pública, pelos ministros, dos casos em discussão.

Estudos existentes mostraram que as atitudes dos juízes em relação às regras internas de procedimentos do Tribunal são notoriamente frouxas quando se trata de certos poderes que eles têm sobre a agenda do tribunal. ${ }^{68}$ Isso cria espaço para um alto nível de informalidade na forma como eles usam essas prerrogativas, como o uso desses poderes na negociação entre os ministros em um grande número de casos. Em tal cenário, mais uma vez, o comportamento com viés de gênero pode estar em jogo. Neste artigo, investigamos se os juízes tenderiam a ser mais agressivos no uso de seus poderes negativos de definição de agenda ("pedidos de vista") quando o relator de caso é do sexo feminino. Com nossos dados atuais, no entanto, não fomos capazes de encontrar nenhum resultado estatisticamente significativo para essa pergunta.

Considerando a presença de apenas três mulheres no STF em todo o período analisado, não podemos realmente excluir, com nossos dados, a possibilidade que os resultados se explicam por características específicas das três ministras individuais que estava no tribunal - e não pelo fato de serem mulheres. Nesse sentido, é importante que futuros estudos retornem a essas mesmas perguntas, conforme o número de mulheres no tribunal for aumentando, para testar essas diferentes explicações para essas variações de comportamento dos ministros quanto às mulheres relatoras.

Na próxima etapa, nesse mesmo projeto de pesquisa, utilizaremos um novo conjunto de dados, incluindo a frequência e a duração das falas e interrupções entre ministros e ministras do STF durante as deliberações e uma série de outras variáveis de controle, como taxas de absenteísmo, duração dos votos, nomeações presidenciais, experiências profissionais anteriores dos ministros e o gênero dos outros ministros (não apenas do relator do caso). Embora este trabalho seja um passo inicial, nossa constatação de que o gênero do relator de caso pode explicar padrões de divergência sugere que a dinâmica de gênero é uma variável útil a ser levada em consideração em pesquisas futuras. Além disso, ao apontar uma potencial discriminação de gênero, consciente ou não, dentro de uma instituição que deveria agir como um guardião imparcial dos direitos das mulheres e das minorias, esperamos que nossos resultados contribuam para tornar esse tipo de pesquisa ainda mais urgente.

\section{REFERÊNCIAS}

ALMEIDA, Danilo; BOGOSSIAN, André. Nos termos do voto do relator: considerações acerca da fundamentação coletiva nos acórdãos do STF. Revista Estudos Institucionais, Rio de Janeiro, v. 2, n. 1, p. 263-297,

68 ARGUELHES, Diego Werneck; RIBEIRO, Leandro Molhano. Ministrocracia: o Supremo Tribunal Individual no processo democrático brasileiro. Novos Estudos CEBRAP, v. 37, n. 1, p. 13-32, jan./abr. 2018. 
2016.

ANNENBERG, Flávia Xavier. Gender-based provisions in the united states and in Brazil: tensions between the anti-stereotyping doctrine and the positive discrimination approach. Artigo inédito, 2017.

ARAÚJO, Heloisa Bianquini. Qual o gênero do Supremo?: diálogo institucional nas sabatinas para o STF, poder e profissionalismo. 2015. 264 f. Monografia (Graduação) - Faculdade de Direito, Universidade de São Paulo, São Paulo, 2015.

ARGUELHES, Diego Werneck; HARTMANN; Ivar A. Timing control without docket control: how individual justices shape the Brazilian Supreme Court's agenda. Journal of Law and Courts, Chicago, v. 5, n. 1, p. 105-140, mar./maio 2017.

ARGUELHES, Diego Werneck; RIBEIRO, Leandro Molhano. 'The Court, it is I'?: individual judicial powers in the Brazilian Supreme Court and their implications for constitutional theory. Global Constitutionalism, v. 7, n. 2, p. 236-262, 2018.

ARGUELHES, Diego Werneck; RIBEIRO, Leandro Molhano. Ministrocracia: o Supremo Tribunal Individual no processo democrático brasileiro. Novos Estudos CEBRAP, v. 37, n. 1, p. 13-32, jan./abr. 2018.

ARGUELHES, Diego Werneck; RIBEIRO, Leandro Molhano. O Supremo Individual: mecanismos de atuação direta dos ministros sobre o processo político. Direito, Estado e Sociedade, Rio de Janeiro, v. 46, p. 121-155, jan./jun. 2015.

BARROSO, Luís Roberto. Constituição, democracia e supremacia judicial: direito e política no Brasil contemporâneo. Revista da Faculdade de Direito-UERJ, v. 2, n. 21, jan./jun. 2012.

BONELLI, Maria da Glória. Brazilian judges in-between professionalism, gender and difference. International Journal of the Legal Profession, v. 22, n. 2, p. 134-150, Apr. 2015.

BONELLI, Maria da Glória. Carreiras jurídicas e vida privada: interseções entre trabalho e família. Cadernos Pagu (UNICAMP), Campinas, n. 46, p. 245-277, jan./abr. 2016.

BONELLI, Maria da Glória. Profissionalismo e diferença de gênero na magistratura paulista. Civitas: Revista de Ciências Sociais, Porto Alegre, v. 10, n. 3. p. 270-292, set./dez. 2010.

BONELLI, Maria da Glória. Profissionalismo, diferença e diversidade na advocacia e na magistratura paulistas. Revista Brasileira de Ciências Sociais, São Paulo, v. 28, n. 83, p. 125-140, out. 2013.

CASELLA, George; BERGER, Roger L. Statistical inference. 5. ed. Belmont: Duxbury, 2002.

CASTILHO, Ela Wiecko Volkmer de. Criminalização do tráfico de mulheres: proteção das mulheres ou reforço da violência de gênero?. Cadernos Pagu, Campinas, n. 31, p. 101-123, jul./dez. 2008.

CHADA, Daniel; HARTMANN, Ivar. A distribuição de processos no Supremo é realmente aleatória?, 2016. Disponível em: < https://jota.info/colunas/supra/distribuicao-dos-processos-no-supremo-e-realmente-aleatoria-25072016>. Acesso em: 15 jun. 2018

COMISSÃO DE CONSTITUIÇÃO, JUSTIÇA E CIDADANIA. Ata da 11 a Reunião Ordinária, da $52^{a}$ Legislatura realizada em 10 de maio de 2006.

COMISSÃO DE CONSTITUIÇÃO, JUSTIÇA E CIDADANIA. Ata da da $2^{a}$ Sessão Legislativa Extraordinária, da 51 Legislatura, realizada em 21 novembro de 2000.

COMISSÃO DE CONSTITUIÇÃO, JUSTIÇA E CIDADANIA. Reunião Extraordinária da Comissão de Constituição, Justiça e Cidadania da $1^{a}$ Sessão Legislativa Ordinária da 54ª Legislatura,64., 6 de dezembro de 2011.

CONSELHO NACIONAL DE JUSTIÇA. Censo do poder judiciário. Brasília: CNJ, 2014. 
DIAS, Maria Berenice. A Lei Maria da Penha na justiça: a efetividade da Lei 11.340/2006 de combate à violência doméstica e familiar contra a mulher. São Paulo: Revista dos Tribunais, 2007.

DIMOULIS, Dimitri; LUNARDI, Soraya. A tendência passivista do Supremo. In: FALCÃO, Joaquim; ARGUELHES, Diego Werneck; RECONDO, Felipe (Org.). O Supremo em 2015. Rio de Janeiro: FGV, 2016. p. 303-306.

DOLAN, Kathleen A. When does gender matter? Women candidates and gender stereotypes in American elections. New York: Oxford University Press, 2014

EAGLY, Alice; CARLI, Linda L. Women and the labyrinth of leadership. Harvard Business Review, Cambridge, v. 85, n. 9, p. 62-67, Sep. 2007.

EPSTEIN, Lee; LANDES, William; POSNER, Richard A. Why (and when) judges dissent: a theoretical and empirical analysis. Journal of Legal Analysis, Cambridge, v. 3, n. 1, p 101-137, mar. 2011.

FALCÃO, Joaquim; ARGUELHES, Diego Werneck. Onze supremos, todos contra o Plenário. In: FALCÃO, Joaquim; ARGUELHES, Diego Werneck; RECONDO, Felipe (Org.). Onæe supremos: o Supremo em 2016. Rio de Janeiro: FGV, 2017. p. 20-29.

FALCÃO, Joaquim; CERDEIRA, Pablo Camargo; ARGUELHES, Diego Werneck. I Relatório Supremo em números: o múltiplo Supremo. Rio de Janeiro: FGV, 2011.

FALCÃO, Joaquim; CERDEIRA, Pablo Camargo; ARGUELHES, Diego Werneck. O Supremo Tribunal Federal Processual. In: MARTINS, Ives Gandra S.; ROSSET, Patricia; AMARAL, Antonio Carlos R. (Org.). Estudos: Direito Público. Homenagem ao Ministro Carlos Mário da Silva Velloso. São Paulo: Lex Magister, 2013. p. 299-308.

FALCÃO, Joaquim; HARTMANN, Ivar A.; CHAVES. Vitor P. III Relatório Supremo em números: O Supremo e o tempo. Rio de Janeiro: FGV, 2014.

FONTAINHA, Fernando et al. História oral do Supremo Tribunal Federal. Rio de Janeiro: FGV, 2015-2016.

FRAGALE FILHO, Roberto; MOREIRA, Rafaela Selem; SCIAMMARELLA, Ana Paula de O. Magistratura e gênero: um olhar sobre as mulheres nas cúpulas do judiciário brasileiro, 2015. Disponível em: < https:// journals.openedition.org/eces/1968>. Acesso em: 15 jun. 2016

FREITAS, Lúcia; LOIS, Cecilia Caballero. Acórdãos do STF sobre Lei Maria da Penha: um estudo piloto da relação direito, gênero e linguagem. In: OLIVEIRA JUNIOR, José Alcebíades de; MENDES, Regina Lucia Teixeira; SCAMARELLA, Maria Luisa (Org.). Sociologia, antropologia e cultura jurídicas. Curitiba: CONPEDI/ UNICURITIBA, 2013. p. 247-265.

GLICK, Peter; FISKE, Susan T. Sex discrimination: the psychological approach. In: CROSBY, Faye et al (Ed.). Sex discrimination in the workplace: multidisciplinary perspectives. Malden, MA: Blackwell, 2007.

GOMES, Juliana Cesario Alvim. O Supremo Tribunal Federal em uma perspectiva de gênero: mérito, acesso, representatividade e discurso. Direito \& Práxis, Rio de Janeiro, v. 7, n. 3, p. 652-676, jul./set. 2016.

GREZZANA, Stefânia. Viés de Gênero no Tribunal Superior do Trabalho Brasileiro. 2011. 61f. Dissertação (Mestrado) - Escola de Economia de São Paulo, FGV, São Paulo, 2011.

GUINIER, Lani; MINOW, Martha. Dynamism, Not Just Diversity. Harvard Journal of Law \& Gender, Cambridge, v. 30, n. 2, p. 269-277, Jun./Nov. 2007.

GUJARATI, D. N. Basic econometrics. Tata McGraw-Hill Education, 2009.

HARTMANN, Ivar A.; FERREIRA, Lívia. Ao relator, tudo: o impacto do aumento do poder do ministro relator no Supremo. Opinião Jurídica, Fortaleza, v. 13, n. 17, p. 268-283, jan./dez. 2015. 
INSTITUTO BRASILEIRO DE GEOGRAFIA E ESTATÍSTICA. Estatísticas de gênero: uma análise do Censo Demográfico 2010. Rio de Janeiro: IBGE, 2014.

JACOBI, Tonja; SCHWEERS, Dylan. Justice. Interrupted: the effect of gender, ideology and seniority at Supreme Court oral arguments. Virginia Law Review, v. 103, p. 1379-1485, 2017.

JUNQUEIRA, Eliane Botelho. Women in the judiciary: a perspective from Brazil. In: SCHULTZ, Ulrike; SHAW, Gisela (Org.). Women in the world's legal professions. Oxford: Hart, 2003.

KENNEY, Sally J. Gender \& Justice: Why women in the Judiciary really matter. New York: Routledge, 2013.

MACHADO, Marta Rodriguez de Assis; BRACARENSE, Ana Carolina. O caso do feto anencefálico: direitos sexuais e reprodutivos, confronto e negociação argumentativa no Supremo Tribunal Federal. Direito \& Práxis, Rio de Janeiro, v. 7, n. 3, p. 677-714, jul./set. 2016.

MENDES, Conrado Hubner. O projeto de uma corte deliberativa. In: VOJVODIC, Adriana; PINTO, Henrique Motta; PAGANI, Rodrigo (Org.). jurisdição constitucional no Brasil. São Paulo: Malheiros, 2012.

MENDES, Conrado Hubner. The Supreme Federal Court of Brazil. In: JAKAB, András; DYEVRE, Arthur; ITZCOVICH, Giulio (Org.). Comparative constitutional reasoning. Nova York: Cambridge University Press, 2017.

MIGUEL, Luís Felipe; BIROLI Flávia. Feminismo e política: uma introdução. São Paulo: Boitempo, 2014.

MOSS-RACUSIN, Corinne A. Science faculty's subtle gender biases favor male students. Proceedings of the National Academy of Sciences, v. 109, n. 41, p. 16474-16479, 2012.

MOSS-RACUSIN, Corinne. A.; RUDMAN, Laurie. A. Disruptions in women's self-promotion: the backlash avoidance model. Psychology of Women Quarterly, Piscataway, v. 34, n. 2, p. 186-202, apr./jun. 2010.

OLIVEIRA, Fabiana Luci de. Supremo relator: processo decisório e mudanças na composição do STF nos governos FHC e Lula. Revista Brasileira de Ciências Sociais, São Paulo, v. 27, n. 80, p.89-115, out. 2012.

PIMENTEL, Silvia; PANDJIARJIAN, Valeria; BELLOQUE, Juliana. "Legítima defesa da honra”, ilegítima impunidade de assassinos: um estudo crítico da legislação e jurisprudência da América Latina. In: CORRÊE, Mariza; SOUZA, Érica Renata (Org.). Vida em família: uma perspectiva comparativa sobre crimes de honra. Campinas: UNICAMP, 2006. p.65-208.

PIOVESAN, Flávia; GONÇALVES, Tamara Amoroso. Gênero no Supremo Tribunal Federal. In: SARMENTO, Daniel; SARLET, Ingo Wolfgang (Org.). Direitos fundamentais no Supremo Tribunal Federal: balanço e crítica. Rio de Janeiro: Lúmen Júris, 2011. p. 367-390.

RESNIK, Judith. On the Bias: Feminist reconsiderations of the aspirations for our judges. Southern California Law Review, Los Angeles, v. 61, n. 6, p. 1877-1944, Sep. 1988.

REUBEN, Ernesto; SAPIENZA, Paola; ZINGALES, Luigi. How stereotypes impair women's careers in science. Proceedings of the National Academy of Sciences, v. 111, n. 12, p. 4403-4408, 2014.

RIBEIRO, Leandro Molhano; ARGUELHES, Diego Werneck. Preferências, estratégias e motivações: pressupostos institucionais de teorias sobre comportamento judicial e sua transposição para o caso brasileiro. Direito e Práxis, Rio de Janeiro, v. 4, n. 7, p. 85-121, out./dez. 2013.

ROSEVEAR, Evan; HARTMANN, Ivar; ARGUELHES, Diego Werneck. Disagreement on the Brazilian Supreme Court. an exploratory analysis. 2015. Disponível em: <https://papers.ssrn.com/sol3/papers. cfm?abstract_id=2629329>. Acesso em: 16 jul. 2018.

RUDMAN, Laurie. A. et al. Status incongruity and backlash effects: defending the gender hierarchy motiva- 
tes prejudice against. Journal of Experimental Social Psychology, v. 48, n. 1, p. 165-179, Jan. 2012.

SADEK, Maria Teresa. Magistrados: uma imagem em movimento. Rio de Janeiro: FGV, 2006.

SCHULTZ, Ulrike; SHAW, Gisela (Org.). Women in the world's legal professions. Oxford: Hart, 2003.

SCHULTZ, Vicki. Reconceptualizing sexual harassment. Yale Law Journal, v. 107, p. 1683-1805, 1998.

SCHULTZ, Vicki. Telling stories about women and work: judicial interpretations of sex segregation in the workplace in Title VII cases raising the lack of interest defense. Harvard Law Review, v. 103, p. 1749-1843, 1990.

SEVERI, Fabiana Cristina. O gênero da justiça e a problemática da efetivação dos direitos humanos das mulheres. Direito e Práxis, Rio de Janeiro, v. 7, n. 1, p. 80-115 jan./mar. 2016.

SHIELDS, Stephanie. A. Speaking from the heart. gender and the social meaning of emotion. Cambridge: Cambridge University Press, 2002.

SILVA, Virgilio Afonso da. Deciding without deliberating. International Journal of Constitutional Law, New York, v. 11, n. 3, p. 557-584, Jul. 2013.

SILVA, Virgílio Afonso da. Do we deliberate?: if so, how?. European Journal of Legal Studies, Florença, v. 9, n. 2, p. 209-240, 2017.

SILVA, Virgílio Afonso da. O relator dá voz ao STF?: uma réplica a Almeida e Bogossian. Revista Estudos Institucionais, Rio de Janeiro, v. 2, n. 2, p. 648-669, 2016.

SILVA, Virgílio Afonso da. 'Um Voto Qualquer?’: o papel do ministro relator na deliberação no Supremo Tribunal Federal. Revista de Estudos Institucionais, Rio de Janeiro, v. 1, n. 1, p. 180-200, 2015.

SMART, Carol. Las teorías feministas y el discurso jurídico. In: BIRGIN, Haidée et al (Org.). El derecho en el género y el género en el derecho. Buenos Aires: Biblos, 2000.

TORRES, Lise; HUFFMAN, Matt L. Social networks and job search outcomes among male and female professional, technical, and managerial workers. Sociological Focus, v. 35, n. 1, 2002.

TURNER, Charles C. Gender, judging, and the decision to concur: female justices and the Supreme Court. In: ENCONTRO ANNUAL DA “WESTERN POLITICAL SCIENCE ASSOCIATION”, 2015, Las Vegas, Nevada, 2015.

VERÍSSIMO, Marcos Paulo. A Constituição de 1988, vinte anos depois: Suprema Corte e 'ativismo judicial à brasileira'. Revista Direito GV, São Paulo, v. 4, n. 2, p. 407-440, jul./dez. 2008.

VIEIRA, Oscar Vilhena. "Supremocracia”. Revista Direito GV, São Paulo, v. 4, n. 2, p. 441-463, jul./dez. 2008. 
Para publicar na revista Brasileira de Políticas Públicas, acesse o endereço eletrônico www.rbpp.uniceub.br

Observe as normas de publicação, para facilitar e agilizar o trabalho de edição. 